Helgoländer wiss. Meeresunters. 32, 313-358 (1979)

\title{
Populationsdynamik, Produktivität und Energiehaushalt des Wattwurms Arenicola marina (Annelida, Polychaeta)
}

\author{
H. Pollack \\ Rubr-Universität Bochum, Lebrstuhl für Spezielle Zoologie; \\ D-4630 Bochum, Bundesrepublik Deutschland
}

\begin{abstract}
Population dynamics, productivity and energetics of the lugworm Arenicola marina (Annelida, Polychaeta). Dispersion, abundance dynamics, size-frequency, mortality, growth, biomass, productivity, energy flow, germ-cell development, sex ratio, breeding season, natality and fertility of Arenicola marina were investigated from 1975 to 1977 at four intertidal study areas near Roscoff (Brittany, France). Numerical abundance is highest in the upper shore. Here the population consists chiefly of small immature worms. Towards the lower shore, abundance decreases whereas individual size increases. Annual variations in abundance are greatest in the upper shore. Variation in abundance is essentially influenced by wave movement. There is evidence supporting the view that, in spring, small lugworms migrate from the upper part of the shore all over the tidal flat area. Growth rates vary significantly within the areas examined. Generally they increase with increasing duration of submersion. A. marina is the most important producer among the polychaetes so far examined. Productivity is highest in sheltered flats and decreases with increasing disturbance by water movement. Energy budgets of lugworms are estimated. Energy requirements and energy supply are discussed, particularly the extent to which filtration in the headshaft of the burrow may cover food requirements. A brief description of gametogenesis is given. In 1975 at Penpoul the breeding season began in October and lasted two months. At the other study areas - Le Pouldu, Le Guillec and Le Dossen - spawning began in October and lasted one month. In 1976 spawning began earlier but terminated at the same time as in 1975.
\end{abstract}

\section{EINLEITUNG}

Arenicola marina ist eine Charakterart der Wattenboden-Lebensgemeinschaften, die in großer Individuendichte die hochgelegenen, sandigen Wattflächen, die bei Niedrigwasser trockenfallen, besiedelt. Da der Wattwurm ohne Schwierigkeiten in seinem natülichen Lebensraum zu erreichen ist, sind bereits zahlreiche Untersuchungen zur Okologie dieses Polychaeten unternommen worden. Die meisten Arbeiten befassen sich mit der räumlichen Verbreitung und Besiedlungsdichte von $A$. marina an verschiedenen Küsten (Amoureux, 1966; Callame, 1955; Chapmann \& Newell, 1949; Holme, 1949; Linke, 1939; Longbottom, 1970; Pirrie, Bruce \& Moore, 1932; Rullier, 1959; Smidt, 1951; Thamdrup, 1935; Wohlenberg, 1937). Leider lassen diese Arbeiten oft nur in sehr beschränktem Maße eine vergleichende Betrachtung und kausale Aussagen zu, weil entweder die Besiedlungsdichte nicht exakt angegeben (Amoureux, 1966) oder die Außenfaktoren nur sehr unvollkommen 
analysiert wurden (Chapmann \& Newell, 1949; Callame, 1955; Holme, 1949; Longbottom, 1970; Pirrie, Bruce \& Moore, 1932; Wohlenberg, 1937). Ein vertiefter Einblick in die Artenverteilung, ihre Abhängigkeit vom physikalisch-chemischen Faktorengefüge des Lebensraumes sowie die wechselseitigen Beziehungen zwischen verschiedenen Faktoren läßt sich jedoch nur über den Einsatz exakt quantitativer Methoden erreichen.

Das Studium der Entwicklung von Populationen im Jahresablauf ist von wesentlicher Bedeutung für das Verständnis der Lebensprozesse innerhalb einer Biozönose. Erst über die Kenntnis der Populationsdynamik in Raum und Zeit wird auch die Wirkung der sich jahresperiodisch ändernden Umweltfaktoren beurteilbar. Nur wenige Forscher haben bisher populationsdynamische Vorgänge bei A. marina untersucht. Newell (1948) beobachtete die Entwicklung einer Population bei Whitstable und Cazaux (1966) bei Arcachon. Beide Arbeiten lassen jedoch das Gefüge der Außenfaktoren fast völlig unberücksichtigt.

Um zu quantitativen Aussagen über die Bedeutung einer Population innerhalb eines Okosystems zu gelangen, führt man in neuerer Zeit Messungen des Energiehaushaltes bzw. Energieflusses der untersuchten Komponente der Biozönose durch. Bei Verwendung der Kalorie als Maßeinheit* lassen sich die Parameter des Energiehaushaltes, nämlich Produktion, Konsumption und Assimilation verschiedener Arten direkt miteinander vergleichen. Es liegen jedoch bisher nur wenige Arbeiten vor, die sich mit der Produktion einer Art (Burke \& Mann, 1974; Dame, 1976; Hibbert, 1976; Kisseleva, 1972; Klein, Rachor \& Gerlach, 1975; Massé, 1971; Nichols, 1975; Peer, 1970; Rachor, 1976; Teal, 1962) oder der Makrofauna (Hibbert, 1976; Warwick \& Price, 1975) des Eulitorals befassen.

$\mathrm{Da}$ bisher keine Untersuchungen zum Energiefluß bei $A$. marina unternommen worden sind, wird in der vorliegenden Arbeit die räumliche Verteilung, Dynamik und Produktion von Arenicola-Populationen der Kanalkïste Frankreichs dargestellt. Neben den fortlaufenden Untersuchungen der chemischen und physikalischen Faktoren des Lebensraumes wurden zwei Wege mit unterschiedlicher Zielsetzung beschritten. Die Grundlage verallgemeinernder Aussagen über Dispersion und Abundanz bildete die vergleichende Bearbeitung mehrerer Biotope mit unterschiedlicher Beeinflussung durch die Außenfaktoren. Für die Erfassung der dynamischen Prozesse und der Produktion der Lebensgemeinschaft wurden die ausgewählten Gebiete in regelmäßigen Abständen studiert.

In einem weiteren Teil der Arbeit wurden anhand der Befunde zur Populationsdynamik und Produktion sowie der Ergebnisse zusätzlicher Untersuchungen die Assimilation und Konsumption der Arenicola-Populationen errechnet und Energiebilanzen erstellt. Die genaue Darstellung der Untersuchungsgebiete, des chemischen und physikalischen Faktorengefüges sowie die Ergebnisse der Untersuchungen zur Dispersion, Populationsdynamik und Produktion der begleitenden Makro- und Meiofauna sind an anderer Stelle (Pollack, 1978) dargestellt.

\section{MATERIAL UND METHODE}

Um die Gesetzmäßigkeiten der jahreszeitlichen Entwicklung zu erfassen, wurden von Oktober 1975 bis Oktober 1977 vier Biotope in der Gegend um Roscoff (Bretagne) in

\footnotetext{
* Umrechnung in Joules: $1 \mathrm{cal}=4,19 \mathrm{~J}$
} 
regelmäßigen Abständen bearbeitet. Es sind dies das stark-lotische Watt von Le Dossen, die mittel-lotischen Watten von Le Pouldu und Le Guillec und das schwach-lotische Watt des Port de Penpoul (Abb. 1). Die Auswahl der Untersuchungsgebiete erfolgte nach folgenden Kriterien: (1) Sie weisen auf gleichem Niveau zur Wasserlinie eine homogene Besiedlungsdichte durch Arenicola marina L. auf. (2) Sie liegen in unterschiedlicher Exposition zu verschiedenen Außenfaktoren, insbesondere zur Wasserbewegung, Sedimentzusammensetzung, Nährstoffgehalt des Sandes und Salzgehalt des Wassers.

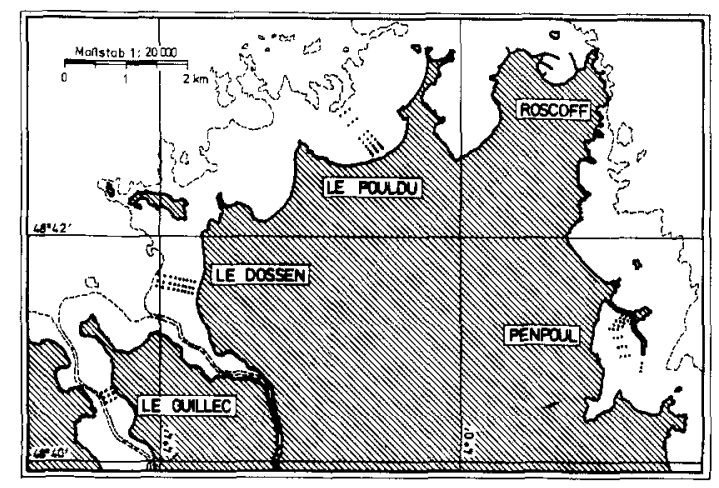

Abb. 1: Ubersichtskarte der Gegend um Roscoff mit den Untersuchungsgebieten Le Guillec, Le Dossen, Le Pouldu und Penpoul. Die Probenorte sind durch Punkte gekennzeichnet

Zum Studium der räumlichen Verteilung und Besiedlungsdichte wurden an den Untersuchungsgebieten jeweils drei Profile quer zur Wasserlinie durch das Watt gelegt. An jedem Profil wurden mit Hilfe eines Niveliergerätes zwölf Untersuchungsstationen mit jeweils $50 \mathrm{~cm}$ Höhenunterschied festgelegt. Als Nullinie diente die mittlere Niedrigwasserlinie. Es ergaben sich damit in jedem Untersuchungsgebiet Felder mit gleicher Exposition zur mittleren Niedrigwasserlinie und somit gleicher Wasserbedeckungszeit. Um die Untersuchungsfelder wiederzufinden, wurden Kunststoffleinen, auf denen die Lage der Untersuchungsfelder durch Knoten markiert waren, zwischen markanten, unveränderlichen Punkten gespannt. Abbildung 2 zeigt die Lage der Untersuchungsstationen in den verschiedenen Biotopen. An jeder Station wurden die Kothaufen einer Fläche von zehn bis dreißig nebeneinanderliegenden Quadratmetern gezählt. Dann wurde an jeder zweiten Untersuchungsstation der drei Profile zweimal $1 / 2 \mathrm{~m}^{2}$ Bodenfläche $30 \mathrm{~cm}$ tief ausgehoben und der Sand auf eine Plastikplane geworfen, welche verhinderte, daß die Würmer nach unten entweichen konnten. Der Sand wurde fein zerkrümelt, alle Tiere herausgelesen und in Einweckgläsern gesammelt. Aus der Anzahl der Kothaufen und der Zahl der dann tatsächlich gefundenen Würmer wurde die prozentuale Abweichung der Besiedlungsdichte von der Dichte der Kothaufen ermittelt und hiermit die Werte korrigiert, die durch das Zählen der Kothaufen gewonnen wurden.

Die Größe der Tiere wurde durch Gewichtsbestimmungen ermittelt. Um Fehlerquellen, die aus einem unterschiedlichen Füllungszustand des Darms resultieren können, auszuschalten, wurden die Tiere zunächst 24 Stunden lang zur Kotentleerung in Wasser- 
becken gehalten. Die Würmer wurden anschließend mit Filterpapier so lange oberflächlich abgetrocknet, bis das Filterpapier nicht mehr sichtbar feucht wurde. Da aufgrund fortschreitender Verdunstung das Feuchtgewicht nicht konstant bleibt, wurden Trocknung und anschließende Wägung auf der Analysenschnellwaage stets möglichst schnell und gleichmäßig vorgenommen.

Um den Wassergehalt der Tiere festzustellen, wurden diese nach der FeuchtgewichtsBestimmung in Tiegeln bei $95^{\circ} \mathrm{C}$ im Trockenschrank bis zur Gewichtskonstanz getrocknet. Die Bestimmung des Aschegehaltes erfolgte durch Verbrennung der organischen Substanz im Muffelofen. Dabei wurde die Temperatur schrittweise gesteigert, so daß zunächst die vollständige Verkohlung eintrat. Die anschließende Veraschung wurde bei $650^{\circ} \mathrm{C}$ durchgeführt (Lang, 1955).

Sämtliche Wägungen zur Trocken- und Aschegewichtsbestimmung wurden vollzogen, nachdem die Proben im Anschluß an die Trocknung mindestens drei Stunden im Exsikkator über Silicagel aufbewahrt worden waren.

Das Wachstum der Population wird ausgedrückt durch die $\mathrm{Zu}$ - oder Abnahme an Biomasse pro Quadratmeter in einer bestimmten Zeiteinheit: $\triangle B=$ $\left(\mathrm{N}_{2} \cdot \overline{\mathrm{w}}_{2}-\mathrm{N}_{1} \cdot \overline{\mathrm{w}}_{1}\right) \cdot \Delta \mathrm{t}(\mathrm{N}=$ Zahl der Individuen, $\overline{\mathrm{w}}=$ durchschnittliches Gewicht der Würmer).

Das durchschnittliche Wachstum der Individuen errechnet sich aus der Differenz zwischen den Durchschnittsgewichten aufeinanderfolgender Monate:

$$
\Delta \bar{w}=\left(\sum_{0}^{N} w_{2} / N_{2}-\sum_{0}^{N} w_{1} / N_{1}\right) \cdot \Delta t
$$

Fehleinschätzungen, die durch den Zugang junger Würmer entstehen können, wurden vermieden, indem das Wachstum für jede Altersklasse getrennt ermittelt wurde.

Die Produktion wurde für jeden Monat und jede Altersklasse getrennt ermittelt und zwar nach der Gleichung:

$$
\triangle P\left(t_{1}-t_{2}\right)=\sum_{t=1}^{t=t_{t_{1}}} N \Delta \bar{w}
$$

wobei $\triangle P$ den Produktionszuwachs zum vorangegangenen Monat, $N$ die Individuenzahl/ $\mathrm{m}^{2}$ und $\triangle \overline{\mathrm{w}}$ die Zunahme des Durchschnittsgewichtes im Zeitabschnitt $\mathrm{t}_{1}$ bis $\mathrm{t}_{2}$ darstellt (Crisp, 1971). Die Jahresproduktion ergibt sich durch Addition der Produktionswerte sowohl der Altersklassen als auch der Monate des Jahres.

Der physiologische Brennwert des Arenicola-Gewebes wurde mit Hilfe eines BombeCalorimeters im Centre National des Recherches Zootechniques (Jouy en Josas) ermittelt.

Der für Stoffwechselleistungen aufgewandte Energiebetrag wurde anhand der Respirationsgröße ermittelt. Die Umrechnung des Sauerstoffverbrauchs in Energieäquivalente erfolgte mit Hilfe des Mittelwertes der oxycalorischen Koeffizienten für Proteine, Fette und Kohlehydrate, der angibt, daß $1 \mathrm{~cm}^{3}$ Sauerstoff äquivalent 4,8 cal ist (Ivlev, 1934). Das bedeutet, daß für eine Stoffwechselleistung, bei der $1 \mathrm{~cm}^{3}$ Sauerstoff verbrannt wird, $4,8 \mathrm{cal}$ an Brennstoff notwendig sind. Die Berechnung der Respirationsraten wurden auf der Basis der Untersuchungen von Krüger $(1959,1964)$, welcher experimentell die Abhängigkeit der Sauerstoffaufnahme von der Körpergröße und Temperatur bestimmte, vorgenommen.

Die Kotabgabe wurde an allen Hauptuntersuchungsstationen im Januar, April, Juli und Oktober 1976 quantitativ untersucht. Dazu wurde der von 40 bis 60 Würmern 
Energiehaushalt des Wattwurms

317

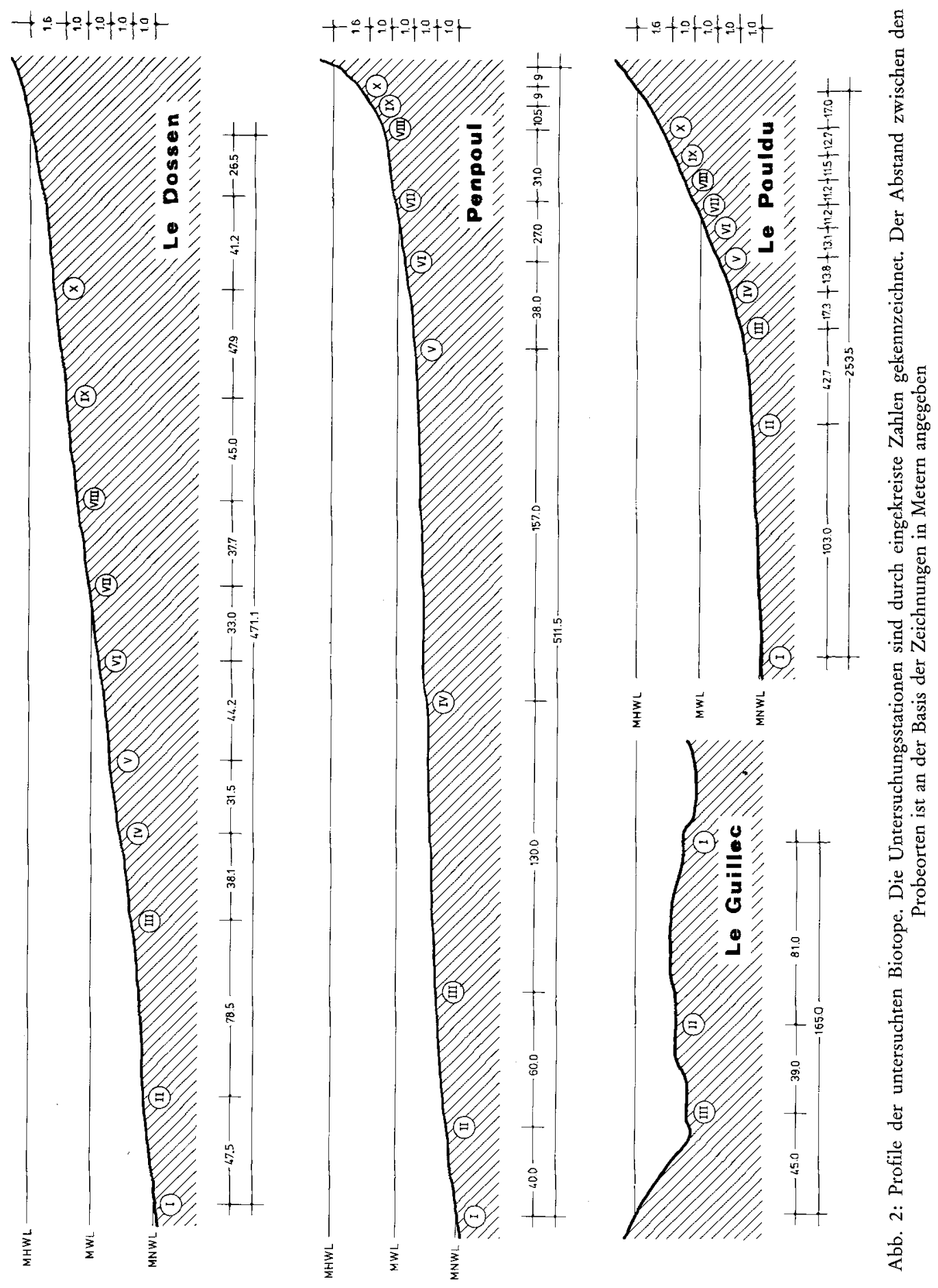


während der Trockenliegephase abgegebene Kot gesammelt. Im Port de Penpoul mußten vorher, d. h. direkt nach Abfließen des Oberflächenwassers, die bestehenden Haufen zerstört werden. An den anderen Biotopen war dies nicht notwendig, da die Haufen bereits durch die Wellenbewegung beseitigt wurden. Unter Berücksichtigung der genauen Zeit zwischen Freilegung der Untersuchungsstation und dem Aufsammeln des Kotsandes, wurden die entsprechenden Tageswerte berechnet.

Um den Einfluß der Gezeiten auf die Aktivität der Würmer zu ermitteln, wurden Aquarienversuche mit simulierter Ebbe und Flut durchgeführt, in denen zehn Tage lang die Kotabgabe von etwa 30 Tieren, sowohl während der Wasserbedeckungs- als auch während der Trockenliegephase quantitativ erfaßt wurde.

Der Energiegehalt der Exkremente wurde aus den Ergebnissen der quantitativen Analyse des Anteils an organisch gebundenem Kohlenstoff nach Walkley \& Black (1934) ermittelt, indem zunächst das Oxygenäquivalent der reduzierten Kaliumdichromatlösung und hieraus mit Hilfe des oxycalorischen Koeffizienten der Kaloriengehalt errechnet wurde (Ivlev, 1935). Da bei der feuchten Oxydation mit Kaliumdichromat nur etwa $80 \%$ des Proteins verbrannt werden, mußten die Werte anschließend korrigiert werden. Die Korrekturfaktoren wurden anhand der Stickstoffwerte, einer durch Ivlev (1934) aufgestellten Tabelle entnommen.

Zur Gewinnung der Geschlechtsprodukte wurden die Würmer mit einer scharfen Pipette angestochen, ein Tropfen Leibeshöhlenflüssigkeit entnommen und dieser mikroskopiert. Der jeweilige Entwicklungszustand wurde anhand der Eigröße und -form, Dottermenge, Spermienplattendurchmesser und -form charakterisiert.

Zur Ermittlung der potentiellen Natalität wurden etwa 100 reife $q q$ verschiedener Größe und Herkunft angeschnitten und das Gesamtgewicht der Coelomflüssigkeit bestimmt. Anschließend wurde das Gewicht eines Tropfens ermittelt und die hierin enthaltenen reifen Eier mit Hilfe einer Zählkammer gezählt. Die Gesamtzahl der reifen Eier eines Wurmes ließ sich aus den so erhaltenen Werten leicht errechnen.

\section{ERGEBNISSE}

\section{$\mathrm{D}$ is persion}

Arenicola marina war an allen Höhenniveaus der ausgewählten Biotope verbreitet. Die größte Besiedlungsdichte befand sich immer zwischen der mittleren Nipphochwasserlinie und der Mittelwasserlinie. Im Watt von Le Pouldu und im Port de Penpoul konnte ein zweites, weitaus geringeres Besiedlungsmaximum ermittelt werden, welches sich besonders ausgeprägt in den Sommermonaten zeigte und sich bei Penpoul etwa in Höhe der mittleren Niedrigwasserlinie, bei Le Pouldu etwa $1 \mathrm{~m}$ darüber erstreckte. Das Watt von Le Dossen wies dagegen nur das höher gelegene Maximum auf.

Die obere Verbreitungsgrenze erstreckte sich in allen Biotopen in Höhe der Nipphochwasserlinie, die untere Verbreitungsgrenze lag etwa 4 bis $6 \mathrm{~m}$ unter der mittleren Niedrigwasserlinie. Wiederholte Tauchuntersuchungen zeigten, daß die Besiedlungsdichte im Sublitoral das ganze Jahr über mit höchstens 2 Individuen $/ \mathrm{m}^{2}$ gering blieb. Dieser Bereich wurde deshalb in den weiteren Ausführungen nicht berücksichtigt. Für die stärker 
besiedelten Untersuchungsorte wurde ein mittlerer Dispersionskoeffizient von 1,7 ermittelt, wodurch eine zufällige Verteilung der Würmer angezeigt ist.

\section{Abundanzdynamik}

Le Pouldu: Das mittel-latische Watt von Le Pouldu war, bezogen auf einen $1 \mathrm{~m}$ breiten Streifen, der von der mittleren Niedrigwasser- bis zur mittleren Hochwasserlinie reicht, im Jahresmittel mit 17 Tieren $/ \mathrm{m}^{2}$ besiedelt. Es wies damit die größte Populationsdichte aller untersuchten Gebiete auf.

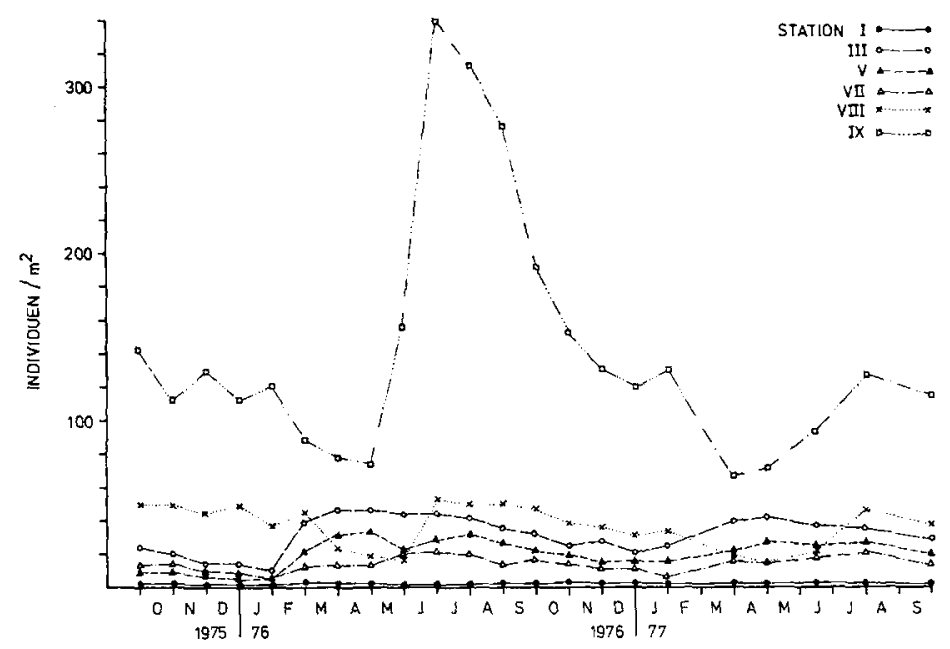

Abb. 3: Abundanzdynamik der Population im Watt von Le Pouldu an den verschiedenen Untersuchungsstationen

Der Jahresverlauf der Abundanzwerte an den verschiedenen Untersuchungsstationen ist in der Abbildung 3 dargestellt. Es fällt auf, daß die Kurven für die Stationen VIII und IX einen prinzipiell ähnlichen Verlauf haben, der stark von dem der übrigen Kurven abweicht. Im oberen Gezeitenbereich (Probenorte VIII und IX) lag die geringste Besiedlungsdichte im April vor. Im Mai und Juni nahm die Individuendichte stark zu und erreichte Anfang Juli die höchsten Werte des Jahres. Anschließend sank sie stark, während der Wintermonate dann gleichmäßig und nur leicht ab. Im Februar und März war dann noch einmal ein stärkerer Abfall der Ábundanzwerte zu verzeichnen.

Im unteren und mittleren Gezeitenbereich (Probenorte III, V und VII) war die Besiedlungsdichte Ende Januar am geringsten, stieg im Februar und März steil an und erreichte bereits Ende April (Station III) und im Juni (Station VII) die Höchstwerte des Jahres. Während der Sommermonate sanken die Abundanzwerte in nur sehr geringem Maße, ab Oktober zunächst stärker, im Dezember dann wieder schwächer bis zum Mininum der Besiedlung im Januar ab. 
Ein Vergleich der Abundanzkurven für die beiden aufeinanderfolgenden Untersuchungsjahre zeigt, daß bei prinzipiell gleichbleibendem Kurvenmuster Variationen in der Kurvenhöhe bestehen. So waren 1976/77 die Werte der Populationsdichte im Jahresmittel an den Stationen III, IV, VI, VIII und IX 2, 2,4, 1,6 20 und $26 \%$ niedriger, an den Stationen V und VII 3,9 und 1,5\% höher als 1975/76. Besonders eindrucksvoll war der Unterschied an der Station IX zur Zeit der größten Besiedlung im Juli, wo $197763 \%$ weniger Tiere gezählt wurden als 1976.

Le Dossen : Die mittlere, auf einen $1 \mathrm{~m}$ breiten Profilstreifen bezogene Besiedlungsdichte lag bei 9,5 Tieren $/ \mathrm{m}^{2}$ und war damit deutlich geringer als an den anderen Untersuchungsgebieten.

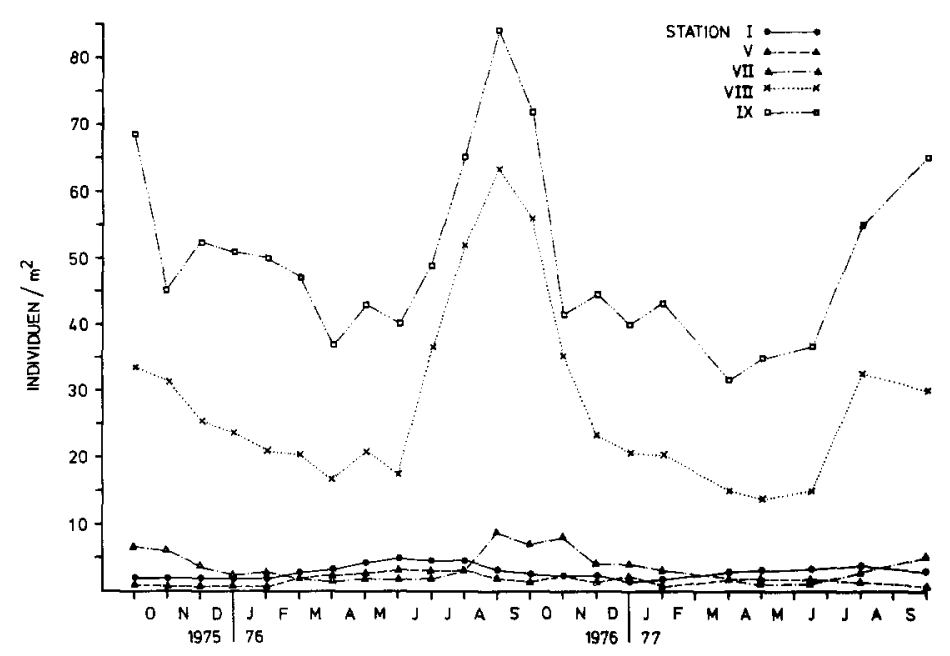

Abb. 4: Abundanzdynamik der Population im Watt von Le Dossen an den verschiedenen Untersuchungsstationen

In Abbildung 4 ist der Jahresgang der Besiedlungsdichte für die verschiedenen Stationen dargestellt. Die Abundanzwerte für die Probenorte II, III und IV sind fast gleich jenen des Probenortes I. Sie sind zur besseren Ubersicht nicht in die graphische Darstellung aufgenommen worden. Wie bei Le Pouldu, so haben auch bei Le Dossen die Kurven für die Untersuchungsorte des oberen Gezeitenabschnitts einen ähnlichen Verlauf, der stark von dem der übrigen Kurven abweicht. Auch hier nimmt die Besiedlungsdichte im oberen Abschnitt (Probenorte VIII und IX) während der Wintermonate, besonders aber im Februar und März, stärker ab als in den vorangegangenen Monaten, wohingegen die des unteren und mittleren Abschnitts (Probenorte I bis VII) zunimmt. Das Besiedlungsmaximum wird im oberen Bereich allerdings erst zwei Monate später crreicht als bei Le Pouldu.

Die Abundanzwerte waren im Jahresmittel 1976/77 an den Stationen I, II, III, V, VIII und IX 3,3, 2,8, 4,5, 4,8, 6,2, 13,6 und $12 \%$ geringer, an den Stationen IV und VII hingegen 2,1 und $5,3 \%$ höher als $1975 / 76$.

Port de Penpoul: Die mittlere auf einen $1 \mathrm{~m}$ breiten Profilstreifen bezogene Besiedlungsdichte war mit 16,7 Tieren $/ \mathrm{m}^{2}$ fast genauso groß wie bei Le Pouldu. Jedoch 
war im Port de Penpoul der untere Gezeitenbereich wesentlich stärker, der mittlere und obere hingegen schwächer besiedelt als bei Le Pouldu.

Ähnlich starke Unterschiede der Abundanzkurven des oberen sowie des mittleren und unteren Gezeitenbereiches, wie sie für Le Dossen und Le Pouldu bestehen, waren hier nicht feststellbar. Die Abundanzkurven der Probenorte des unteren und mittleren

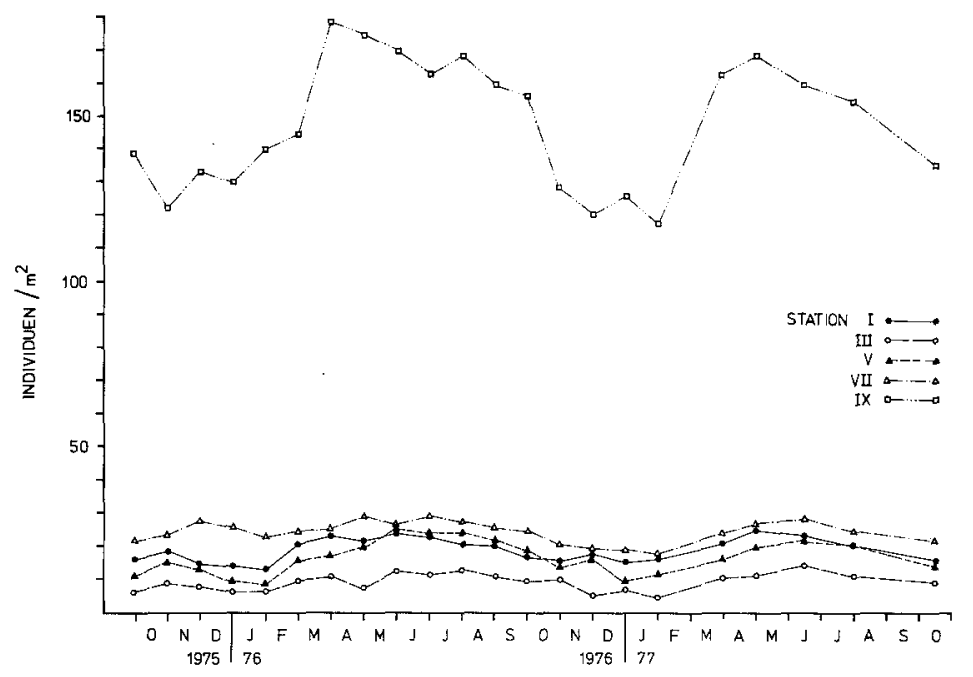

Abb. 5: Abundanzdynamik der Population im Port de Penpoul an den verschiedenen Untersuchungsstationen

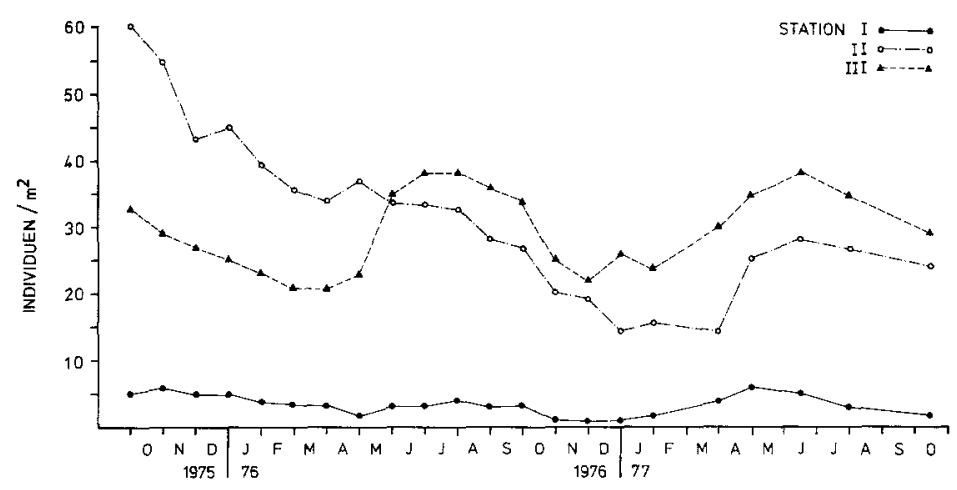

Abb. 6: Abundanzdynamik der Population im Watt von Le Guillec

Abschnitts verlaufen prinzipiell ähnlich wie die des oberen, nur steigen die Besiedlungswerte nach dem Besiedlungstief im Januar allmählich bis Juni (Station I und III) bzw. Juli (Station V und VII) an, während sie im oberen Gezeitenbereich bereits im April das Besiedlungsmaximum des Jahres erreichen (Abb. 5). 
Die für die beiden Untersuchungsjahre errechneten mittleren Abundanzwerte weichen nicht signifkant voneinander ab. Sie waren 1976/77 an den Stationen I, II, V, VII, VIII und IX 2,6,1,9,5,8,12,9,2,4 und $6 \%$ kleiner, an den Stationen III, IV und VI hingegen $4,4,7,2$ und 3,5\% größer als $1975 / 76$.

Le Guille c: Die Besiedlungsdichte lag an den Stationen II und III im Jahresmittel zwischen den Werten der Stationen VIII von Le Pouldu und Penpoul, welche mit den Probenorten von Le Guillec ein gleiches Höhenniveau aufweisen. Die Station I, die unmittelbar neben dem Flußbett liegt und somit den größten Salzgehaltsschwankungen unterworfen ist, wies eine wesentlich geringere mittlere Individuendichte auf.

Die Abundanzkurve für den Probenort III zeigt einen ähnlichen Verlauf wie die für den Probenort VIII von Le Dossen. Allerdings ist hier das Besiedlungsmaximum geringer ausgeprägt und wird etwa einen Monat früher erreicht (Abb. 6). Dieser typische Verlauf der Abundanzkurve wurde am Probenort II nur für das zweite Untersuchungsjahr ermittelt. Im ersten Jahr nahm hier die Besiedlungsdichte fortlaufend ab. Das Besiedlungsmaximum wurde gleich im ersten Untersuchungsmonat ermittelt. Es ist möglich, daß die Werte der ersten drei Monate von den wirklichen abweichen, da die Ermittlungsmethode danach verfeinert wurde. Im zweiten Jahr nahm die Besiedlungsdichte dann im April und Mai wieder zu. Die Populationsdichte war im zweiten Untersuchungsjahr an den Stationen I und II 28 und $46 \%$ geringer, an der Station III hingegen $2 \%$ höher als im ersten.

Gewichtsverteilung und Altersaufbau der Population

In Arenicola-Populationen unterscheiden sich die Individuen lediglich durch Farb-, Gewichts- und Geschlechtsmerkmale. Im Gegensatz zu vielen Fischen und Mollusken, die jahresringanaloge Strukturen ausbilden, kann das Alter der Arenicola-Individuen nicht direkt bestimmt werden. Altersermittlungen wurden daher in ähnlichen Fällen meist durch Längen- oder Gewichtsmessungen ersetzt. In dieser Arbeit wird der Gewichtshabitus der Populationen in Form von Gewichtsgruppendiagrammen (size-frequency histograms), welche die Beziehung der Häufigkeit zum Gewicht in einem bestimmten Zeitpunkt wiedergeben, dargestellt. $\mathrm{Da} A$. marina nur eine relativ kurze Fortpflanzungsperiode im Jahr hat, geben die'Gewichtsgruppen exakt das Alter wieder und werden auch als Jahresklassen bezeichnet.

Die Würmer in den verschiedenen Biotopen variieren stark in ihrer Größe. So wurden bei Penpoul und Le Dossen im allgemeinen größere Tiere gefunden als bei Le Pouldu. Allerdings waren die Tiere in den verschiedenen Bereichen eines Wattgebietes nicht gleich groß. Die größten Individuen wurden immer im unteren Abschnitt gefunden. Mit steigendem Niveau nahm das mittlere Körpergewicht generell ab. So wogen die auf unterem Niveau lebenden Tiere bei Penpoul, Le Dossen und Le Pouldu durchschnittlich 6,5, 6,0 und 2,3 Gramm, im mittleren Bereich hingegen 2,8,5,5 und 1,7 und im oberen Abschnitt $0,8,0,5$ und 0,8 Gramm. Während die Würmer von Le Dossen und Penpoul in der Nähe der mittleren Niedrigwasserlinie etwa die gleiche mittlere Größe aufwiesen, waren sie im mittleren Gezeitenabschnitt bei Penpoul erheblich kleiner. Im oberen Abschnitt waren sie bei Penpoul und Le Pouldu etwa gleich groß und damit fast doppelt so groß wie bei Le Dossen. 
In den meisten Monaten waren auf gleichem Nieveau zwei, zur Zeit des Zugangs der neuen Würmer aus der letzten Fortpflanzungsperiode drei Gewichtsgruppen, nämlich die Jahresklassen 0, 1 und 2 zu erkennen (Abb. 7-9). Bei Le Guillec konnte in einigen Sommermonaten noch eine vierte Gruppe unterschieden werden. Es ist durchaus möglich,

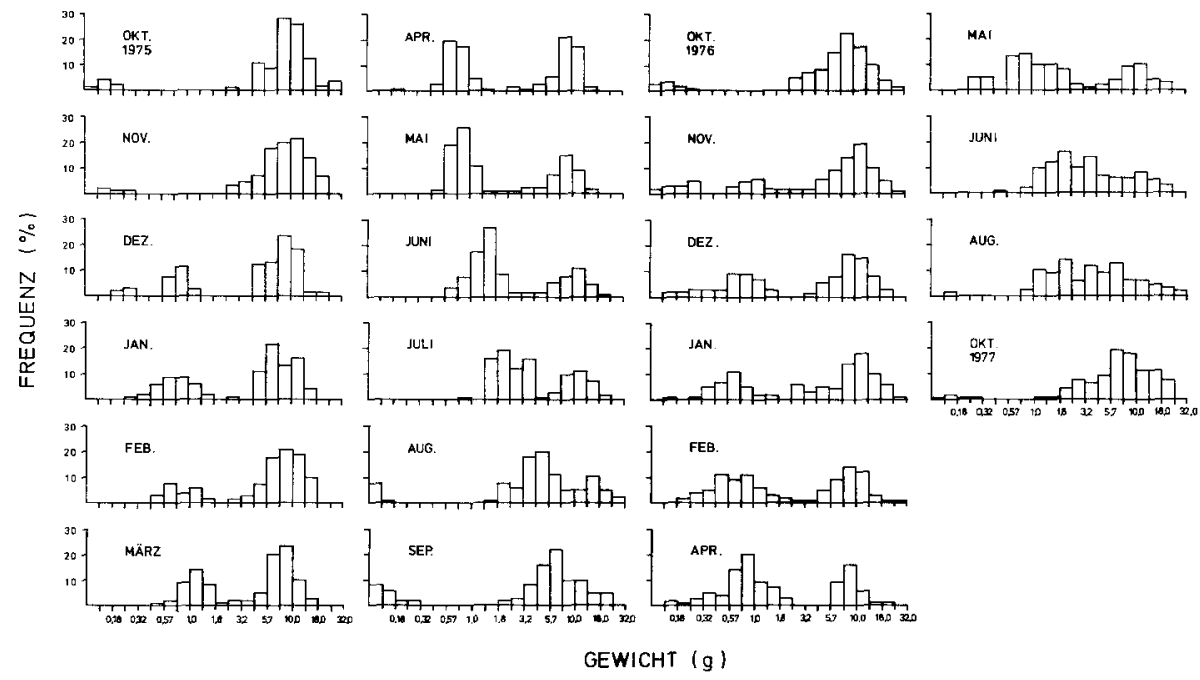

Abb. 7: Gewichtsverteilung der Population im Watt von Le Dossen im unteren Gezeitenbereich (Station I)

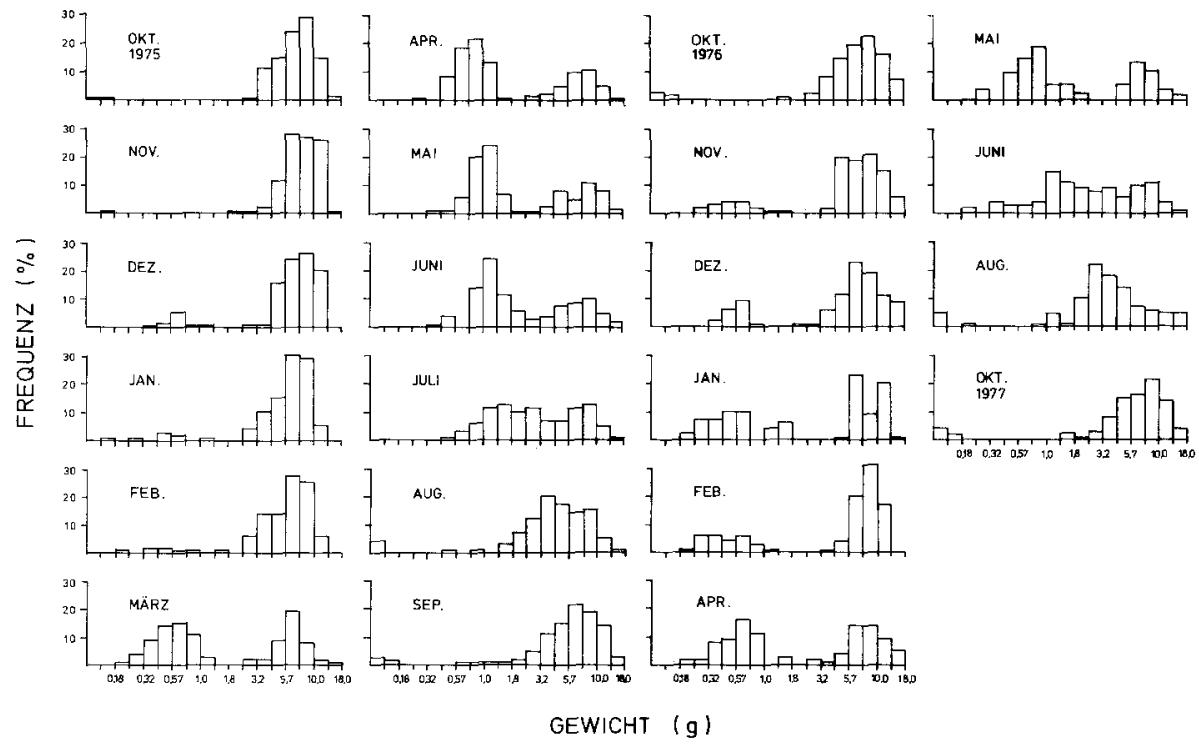

Abb. 8: Gewichtsverteilung der Population im Watt von Le Dossen im mittleren Gezeitenbereich (Station V) 
$\mathrm{da} ß$ an den anderen Biotopen ebenfalls vier oder sogar noch mehr Altersklassen vorlagen, nur ließen sich diese nicht mehr von der Jahresklasse 2 unterscheiden. Es wurden deshalb die dreijährigen und älteren Würmer in einer Gewichtsklasse behandelt.

Im mittleren und unteren Abschnitt der Wattgebiete gehörten im Oktober bis November fast alle Tiere der Jahresklasse 2 an. Während der Wintermonate nahm die Individuendichte der Klasse 1 zunächst allmählich, im Februar und März stärker zu, und zwar in dem Maße, wie die Dichte der Klasse 2 abnahm. Im Sommer tauchte dann bei Le Dossen und Penpoul ein geringer Anteil von Tieren der Klasse 0 auf, der jedoch zum

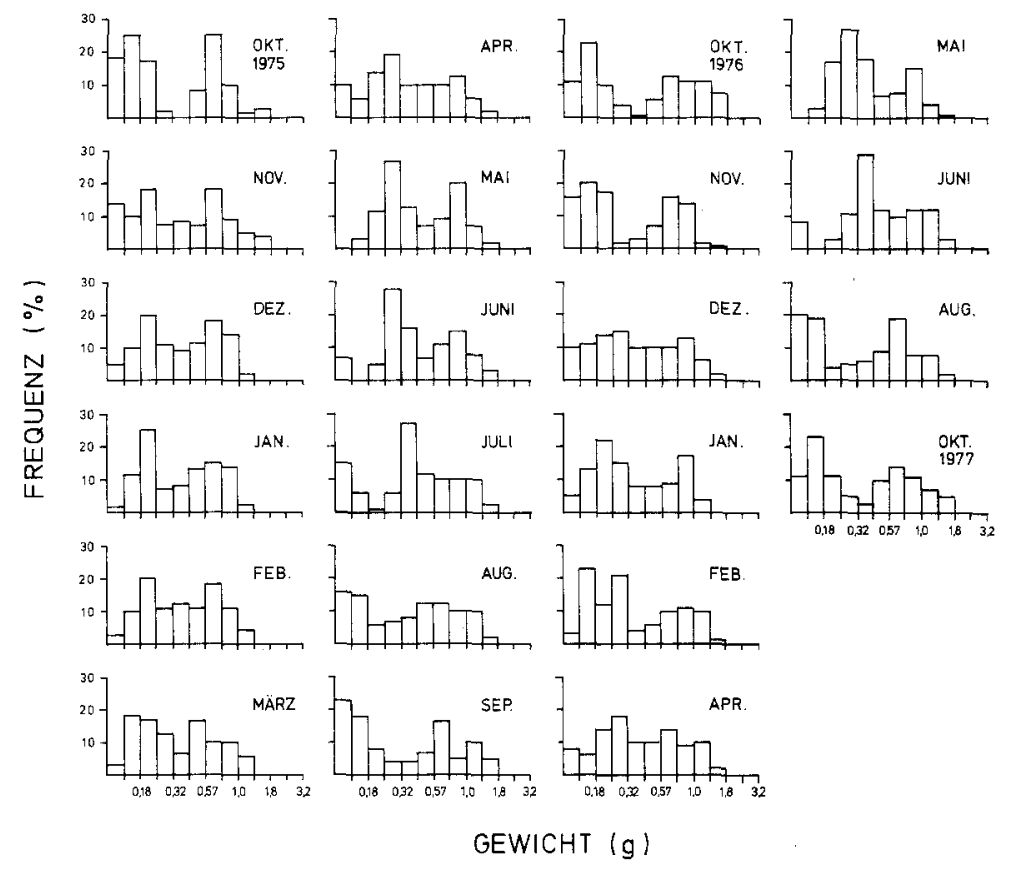

Abb. 9: Gewichtsverteilung der Population im Watt von Le Dossen im oberen Gezeitenbereich (Station IX)

Herbst hin in der Regel verschwindend klein wurde. Die Gewichtsgruppen 1 und 2 vermischten sich und waren etwa ab August bis September nicht mehr voneinander zu unterscheiden.

Im oberen Hang waren in den Wintermonaten die Klassen 1 und 2 etwa gleich stark vertreten. Ab Februar (Penpoul) bzw. Juni (Le Dossen und Le Pouldu) kamen Tiere der Klasse 0 hinzu, welche schnell zahlenmäßig dominierten. Die Tiere der Altersgruppen 1 und 2 waren auch hier während der Sommermonate kaum noch voneinander zu unterscheiden. Die Abbildungen 7 bis 9 zeigen den Gewichtshabitus der Population im Watt von Le Dossen. Die Diagramme für die anderen untersuchten Populationen sind an anderer Stelle dargestellt (Pollack, 1978). 


\section{Wachstum}

Das stark-lotische Watt von Le Dossen wies in den beiden Untersuchungsjahren sowohl im unteren als auch im mittleren und oberen Gezeitenbereich mit 18,6 (16,7), 10,9 $(11,7)$ und 26,6 $(22,7) \mathrm{g}$ Feuchtsubstanz $\mathrm{m}^{-2}$ die geringste mittlere Biomasse der untersuchten Gebiete auf (in Klammern die Werte für das zweite Untersuchungsjahr). Es folgten die mittel-lotischen Watten von Le Pouldu mit 77,9 (70,9), 34,7 (33,2), 110,8 (92,8) und Le Guillec (Station III) mit 96,3 $(81,9)$ und der schwach-lotische Port de Penpoul mit 119,3 $(120,8), 39,5(35,2), 121,9(127,0) \mathrm{g} \mathrm{m}^{-2}$. Die Zahlen zeigen, daß die höchsten Werte immer

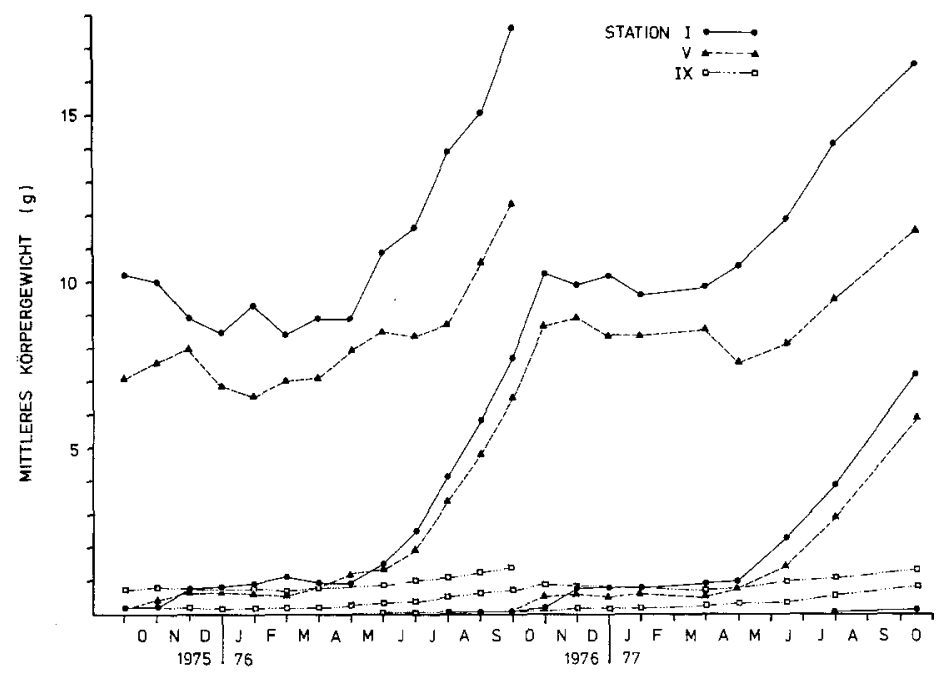

Abb. 10: Jahresverlauf des mittleren Körpergewichts ( $\mathrm{g}$ Feuchtsubstanz) der verschiedenen Generationen im Watt von Le Dossen im unteren (Station I), mittleren (Station V) und oberen (Station IX) Gezeitenbereich

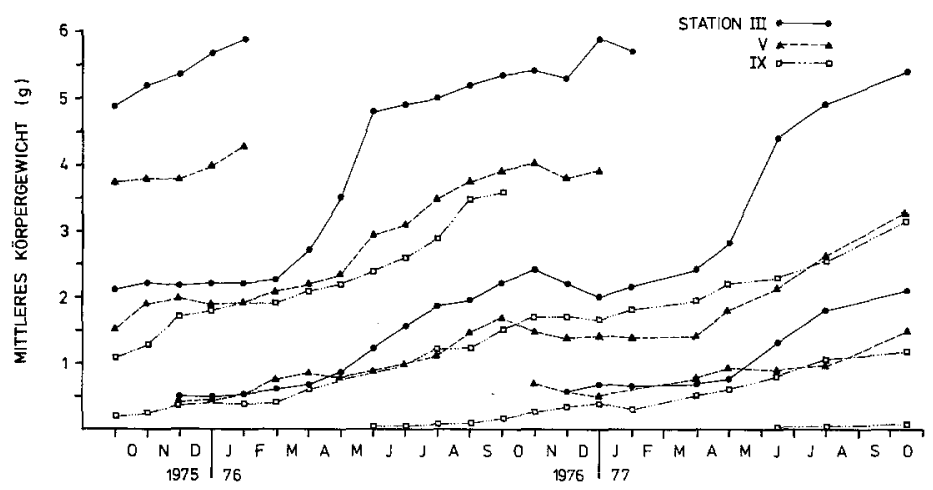

Abb. 11: Jahresverlauf des mittleren Körpergewichts ( $g$ Feuchtsubstanz) der verschiedenen Generationen im Watt von Le Pouldu im unteren (Station III), mittleren (Station V) und oberen (Station IX) Gezeitenbereich 
im oberen Gezeitenabschnitt ermittelt wurden. Im mittleren Bereich waren sie um 50 bis $60 \%$ (Le Dossen), 63 bis $67 \%$ (Le Pouldu) und 67 bis $72 \%$ (Penpoul) geringer. Im unteren Abschnitt wurden wieder höhere Werte festgestellt, die bei Penpoul 1976/77 sogar ebenso groß oder größer waren als die des oberen Abschnitts.

Wie die oben genannten Zahlen verdeutlichen, wurde 1976/77 weniger Biomasse produziert als 1975/76. Besonders deutlich zeigte sich das an den stark- und mittellotischen Watten von Le Dossen, Le Pouldu und Le Guillec, und hier wiederum besonders im oberen Gezeitenbereich. Die im zweiten Untersuchungsjahr ermittelte niedrigere Biomasse war in erster Linie auf schwächer ausgebildete Höchstwerte im Spätsommer zurückzuführen, so vor allem bei Le Guillec III, Le Pouldu IX und Penpoul V. Weiterhin

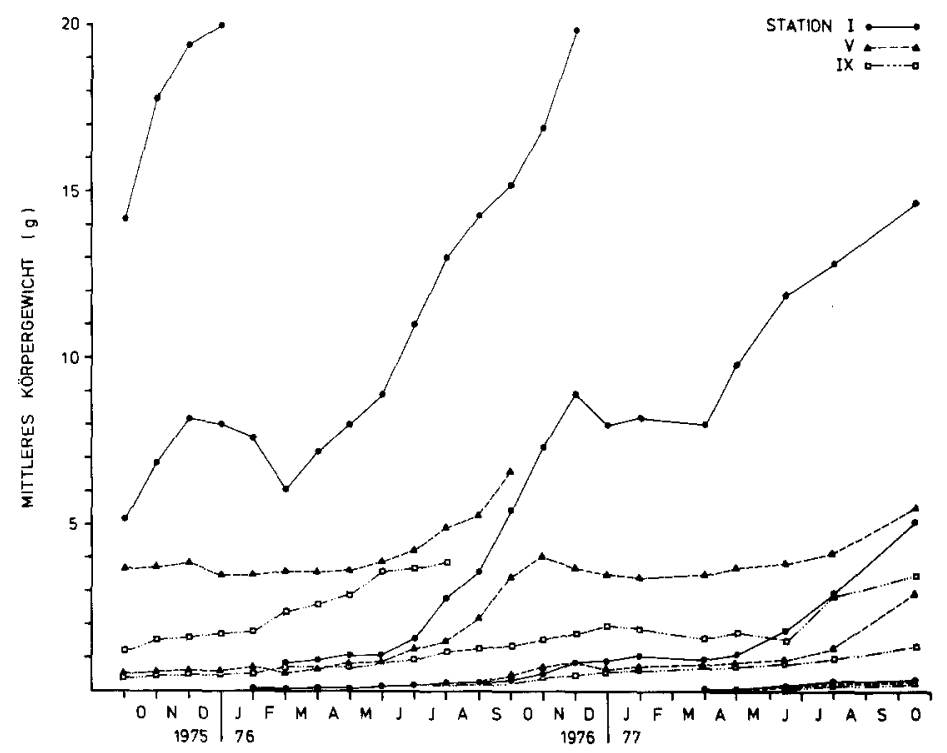

Abb. 12: Jahresverlauf des mittleren Körpergewichts ( $g$ Feuchtsubstanz) der verschiedenen Generationen im Port de Penpoul im unteren (Station I), mittleren (Station V) und oberen (Station IX) Gezeitenbereich

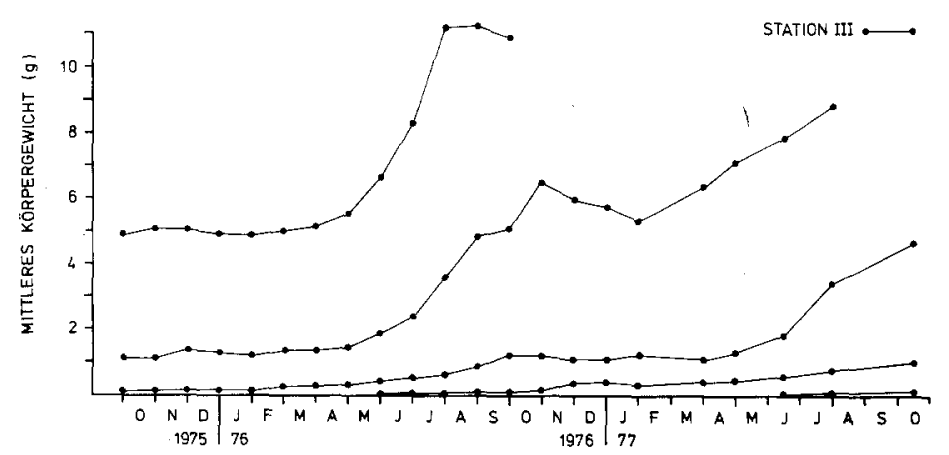

Abb. 13: Jahresverlauf des mittleren Körpergewichts (g Feuchtsubstanz) der verschiedenen Generationen im Watt von Le Guillec 
wurden die Maxima 1977 in der Regel später erreicht als 1976. Die Minima wiesen dagegen in beiden Jahren etwa die gleichen Werte auf.

Das durchschnittliche Wachstum der Individuen variierte zum Teil sehr stark, sowohl von einem Wattgebiet zum anderen, als auch mit unterschiedlichem Höhenniveau eines Biotops. Betrachtet man nur den unteren Gezeitenabschnitt, so waren die größten Zuwachsraten bei Le Dossen zu verzeichnen. Die Tiere der Jahresklasse 1 hatten hier am Ende des ersten Untersuchungsjahres (in Klammern die Werte des zweiten Jahres) durchschnittlich 6,9 (6,4), die der Jahresklasse $210,0(9,4)$ g Feuchtsubstanz zugenommen. Im Port de Penpoul waren in den gleichen Jahresklassen am Ende des Jahres mit 5,0 (4,5) und $10,0(9,3) \mathrm{g} 0$ bis $30 \%$ und bei Le Pouldu mit 1,7 (1,5) und 3,6 (3,2) g sogar 66 bis $76 \%$ weniger Zuwachs zu verzeichnen. Im mittleren Gezeitenabschnitt wurden ebenfalls bei Le Dossen die größten Wachstumsraten mit 5,9 $(5,4)$ und 5,2 $(3,3)$ g ermittelt. Im Port de Penpoul nahmen die Tiere 45 bis $58 \%$, bei Le Pouldu 54 bis $85 \%$ weniger zu.

Im oberen Gezeitenbereich wiesen die Würmer von Penpoul und Le Pouldu mit 0,9 $(1,0)$ bzw. 3,0 $(2,1)$ und $1,1(1,0)$ bzw. 2,5 $(1,6)$ g etwa die gleiche Gewichtszunahme auf. Für die Tiere von Le Dossen, die im unteren und mittleren Abschnitt den größten Zuwachs hatten, wurde hier ein um 49 bis $75 \%$ geringeres Wachstum als an den anderen Biotopen ermittelt.

Wie die oben genannten Zahlen und die Abbildungen 10 bis 13 zeigen, nimmt die Wachstumsgeschwindigkeit generell mit ansteigendem Höhenniveau des Biotops ab. So war der individuelle Gewichtszuwachs bei Le Dossen im mittleren und oberen Gezeitenbereich 15 bis 60 und 92 bis $94 \%$ geringer als im unteren Bereich. Im Port du Penpoul nahmen die Tiere im mittleren und oberen Abschnitt durchschnittlich 41 bis 82 und 78 bis $82 \%$, bei Le Pouldu 26 bis 49 und 24 bis $50 \%$ weniger zu als im unteren Bereich.

Die größten Zuwachsraten waren stets in den Sommermonaten Mai bis Oktober zu verzeichnen (Abb. 10 bis 13). Im Winter war das Wachstum deutlich geringer und oft, besonders bei den Tieren des mittleren und unteren Gezeitenbereiches, sogar eine Abnahme des mittleren Körpergewichts festzustellen. Dies muß aber nicht unbedingt aus einem individuellen Abbau an Körpermasse resultieren, sondern war besonders bei der Jahresklasse 1 wohl auch bedingt durch die Zuwanderung kleinerer Würmer.

Die Wachstumsraten waren im zweiten Untersuchungsjahr geringer als im ersten, was sich besonders deutlich im oberen und mittleren Abschnitt der Biotope zeigte. Die größten Differenzen wurden bei Le Pouldu ermittelt, wo 1976/77 die Würmer der Jahresklassen 1 und 2 auf mittlerem Niveau durchschnittlich 36 und $32 \%$, auf oberem Niveau 9 und $34 \%$ weniger zunahmen als 1975/76. Es folgen der Port de Penpoul mit 15 und 44 bzw. 0 und $19 \%$ und Le Dossen mit 9 und 27 bzw. 5 und $16 \%$ geringeren Zuwachsraten. Aus den oben genannten Zahlen ist weiterhin ersichtlich, daß die älteren Tiere der Jahresklasse $2 \mathrm{im}$ zweiten Untersuchungsjahr in der Regel stärker im Wachstum gehemmt waren als die jüngeren Individuen.

Neben der direkten Ableitung der Zuwachsraten aus den Gewichtsgruppendiagrammen wurde die individuelle Gewichtszunahme an 40 Würmern der Jahresklasse 1 direkt gemessen. Die Tiere wurden von April 1976 bis April 1977 in Kultivierungskästen im Port de Penpoul an der Untersuchungsstation I ausgesetzt und jeden zweiten Monat überprüft. Anfängliche Schwierigkeiten (die Würmer nahmen nicht zu, sondern ab) wurden beseitigt, indem die Kästen nach jedem erneuten Einsetzen mit einer unzerstörten Schicht Oberflä- 
chensand abgedeckt wurden. Es zeigte sich, daß die so ermittelten Wachstumsraten nur geringfügig von den oben dargestellten Werten abweichen.

\section{Sterblichkeit}

Unter Sterblichkeit oder Mortalität wird der durch Tod verursachte Abgang von Populationsgliedern, ausgedrückt durch den Anteil der in der Zeiteinheit Gestorbenen, verstanden. Dieser Anteil, bezogen auf 100 Individuen, wird als Sterberate bezeichnet.

Die Zuwanderung der Würmer während der Wintermonate sowie der Zugang an jungen Würmern über mehrere Frühlings- und Sommermonate hinweg machte die exakte Ermittlung der Sterblichkeit aus den Abundanzwerten für die meiste Zeit des Jahres unmöglich.

Die höchsten Mortalitätsraten wurden an allen Biotopen und Untersuchungsstationen zur Zeit der ersten Herbststürme im Oktober und November ermittelt. Allerdings sind die realen Sterberaten wohl etwas niedriger als die in Tabelle 1 angegebenen Werte, weil nicht entschieden werden konnte, ob die Würmer tatsächlich gestorben oder zum Teil durch starke Sedimentumlagerungen herausgespült und an andere Orte verfrachtet worden waren. Dies trifft besonders für die Untersuchungsstationen IX der stark- und mittellotischen Biotope zu, wo die kleinen Würmer nur wenige Zentimeter unter der Oberfläche leben.

Einen zuverlässigeren Eindruck über die Sterblichkeit ergeben die Daten, die von April 1976 bis April 1977 mit Hilfe von Kultivierungskästen im Port de Penpoul gewonnen wurden. Die Kästen, die $25 \times 20 \times 20 \mathrm{~cm}$ groß und deren Wände maschenartig durchbrochen sind, wurden an einer geschützten Stelle, die in der Nähe der Untersuchungsstation I, also etwa in Höhe der mittleren Niedrigwasserlinie liegt, eingegraben und mit je 1 bis 2 Würmern der Jahresklasse 1 versehen. Insgesamt wurden so 40 Tiere isoliert gehalten und jeden Monat kontrolliert. Die zugewanderten Würmer konnten an dem Gewichtsunterschied erkannt werden und wurden in der Auswertung nicht berücksichtigt. Die Ergebnisse sind ebenfalls in der Tabelle 1 aufgeführt. Die höchsten Mortalitätsraten wurden in den Wintermonaten Januar bis März ermittelt. Im Frühjahr nahm die Sterblichkeit $\mathrm{ab}$ und war im Sommer erheblich niedriger als im Winter.

\section{Produktion}

In diesem Kapitel sind alle Werte als Gewicht der Feuchtsubstanz angegeben. Die entsprechenden Trockengewichts- und Energiegehaltsdaten können der Tabelle 2 entnommen werden. Das aschefreie Trockengewicht wurde an 40 Tieren unterschiedlicher Größe getrennt ermittelt und beträgt im Durchschnitt 14,7\% des Feuchtgewichts.

Die höchsten Produktionswerte wurden im Port de Penpoul sowohl im unteren als auch im mittleren und oberen Gezeitenbereich ermittelt. Es folgen mit sinkender Produktionsleistung das Watt von Le Guillec, Le Pouldu und Le Dossen.

Innerhalb eines Untersuchungsgebietes wies generell der obere Gezeitenbereich hohe Produktionswerte auf. Im mittleren waren sie um 71 bis 79 (Penpoul), 63 bis 65 (Le 
Energiehaushalt des Wattwurms

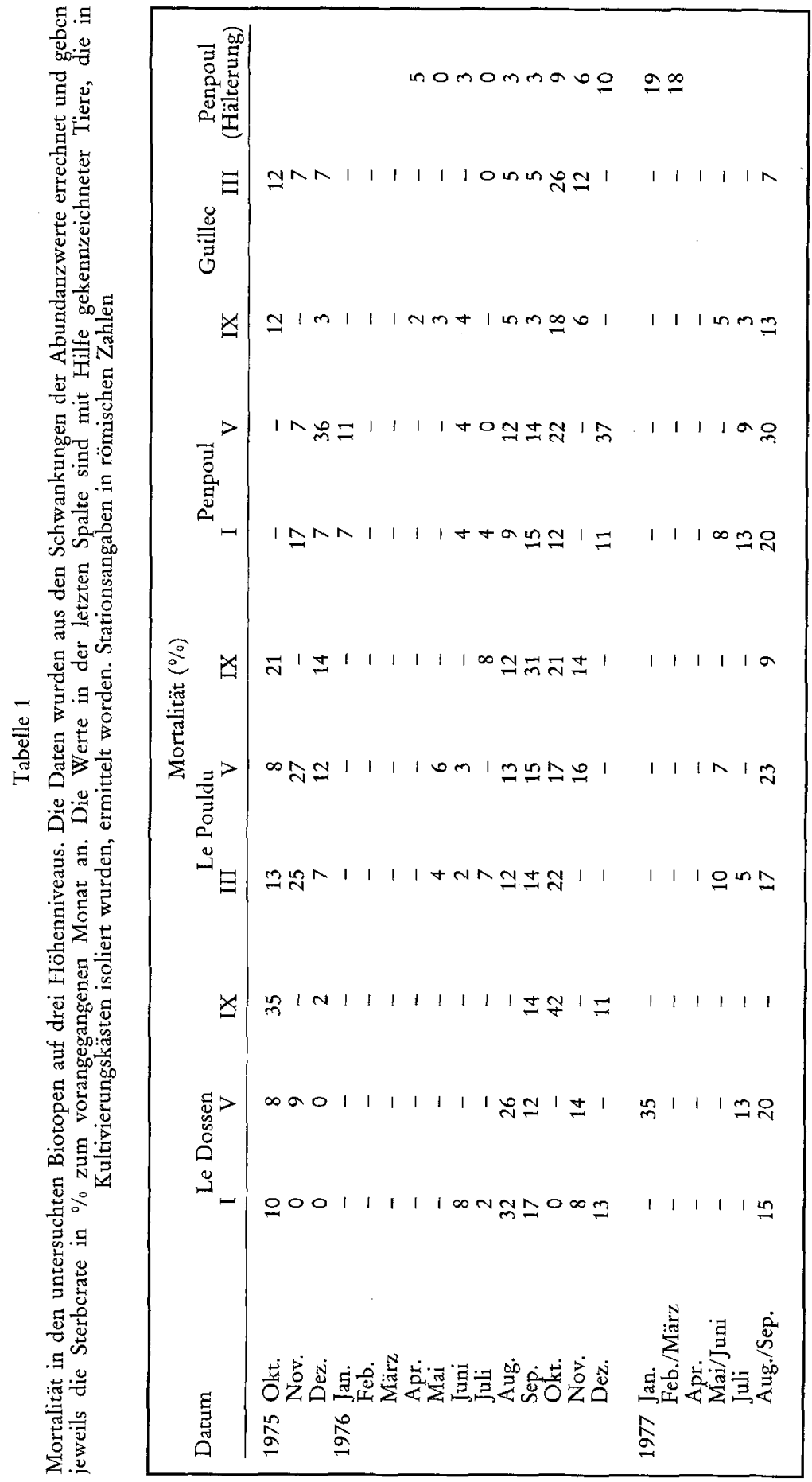


Pouldu) und 39 bis $66 \%$ (Le Dossen) geringer. Im unteren Bereich wurden wieder höhere Werte festgestellt, die im zweiten Untersuchungsjahr bei Penpoul und Le Pouldu größer waren als die für den oberen Bereich.

Die Produktionsleistung war während der Wintermonate gering, in einigen Monaten und Altersklassen gleich Null oder sogar negativ. Das muß aber nicht unbedingt bedeuten, daß Körpermasse abgebaut wurde, sondern kann auch aus einer höheren Sterblichkeit der größeren Tiere der Altersklasse 2 resultieren. Ab April stieg die Produktion an und wies in der Regel im Juni bis Oktober die höchsten Werte auf.

Die Jahresproduktion war an allen Biotopen und Probenorten im zweiten Untersuchungsjahr geringer als im ersten. Dabei wurden die geringsten Unterschiede im unteren Gezeitenabschnitt festgestellt. So waren hier die Produktionsraten 1976/77 bei Le Dossen, Le Pouldu und Penpoul 8, 25 und 15\% kleiner als 1975/76. Im mittleren Abschnitt waren sie im zweiten Jahr 48, 28 und 39 und im oberen Bereich 24, 39 und $31 \%$ geringer als im ersten. Die größte Differenz ergab sich demnach bei Le Dossen und Penpoul für das mittlere und bei Le Pouldu für das obere Wattniveau. Bei Le Guillec III war der Produktionsunterschied zwischen den beiden Jahren mit $38 \%$ ebenfalls beträchtlich. Der Mittelwert der Produktion für alle Biotope und Probenorte lag 1975/76 bei 89,4, 1976/77 hingegen bei $63,1 \mathrm{~g} \mathrm{~m}^{-2}$.

Die Umsatzraten (Turnoverraten) variierten zwischen 0,7 und 1,5 (Tab. 2). Sie waren in der Regel im mittleren Bereich am geringsten und im unteren am höchsten. Im oberen Abschnitt waren sie höher als im mittleren, bei Le Pouldu und Penpoul im ersten Untersuchungsjahr sogar etwas höher als im unteren. Eine Ausnahme bildete Le Dossen, wo 1975/76 der obere Bereich die geringste Turnoverrate aufwies. Wegen der geringeren Produktionswerte waren auch die Umsatzraten im zweiten Untersuchungsjahr geringer als im ersten: Sie lagen 1975/76 im Mittel bei 1,3, 1976/77 hingegen bei 1,0.

\section{Energiehaushalt}

Der Energiehaushalt einer Population wird nach Crisp (1971) durch die Gleichung $\mathrm{C}=\mathrm{P}+\mathrm{R}+\mathrm{F}+\mathrm{U}$ ausgedrückt. Hierbei bedeuten $\mathrm{C}$ die Futterenergie, die von der Population konsumiert wird, $\mathrm{P}$ die Produktion der Energiemenge, welche innerhalb der Population in neuem Gewebe oder in Geschlechtszellen festgelegt wird, R Energieverluste durch den Stoffwechsel, F und U Energieabgaben in Form von Exkrementen.

Die Assimilation (A) ist von Smalley (1960) beschrieben worden als der Teil aufgenommener Energie, der durch die Population für die Produktion von Körpergewebe und Geschlechtszellen (P) und Respiration (R) verbraucht wird: $A=P+R$. Für Assimilation wird auch der Ausdruck Bruttoproduktion geführt.

$$
\text { Energiegehalt des Gewebes }
$$

Zur Umrechnung der Gewichts- in Energieeinheiten mußte der physiologische Brennwert des Arenicola-Gewebes ermittelt werden. Die Analysen wurden mit Hilfe eines 


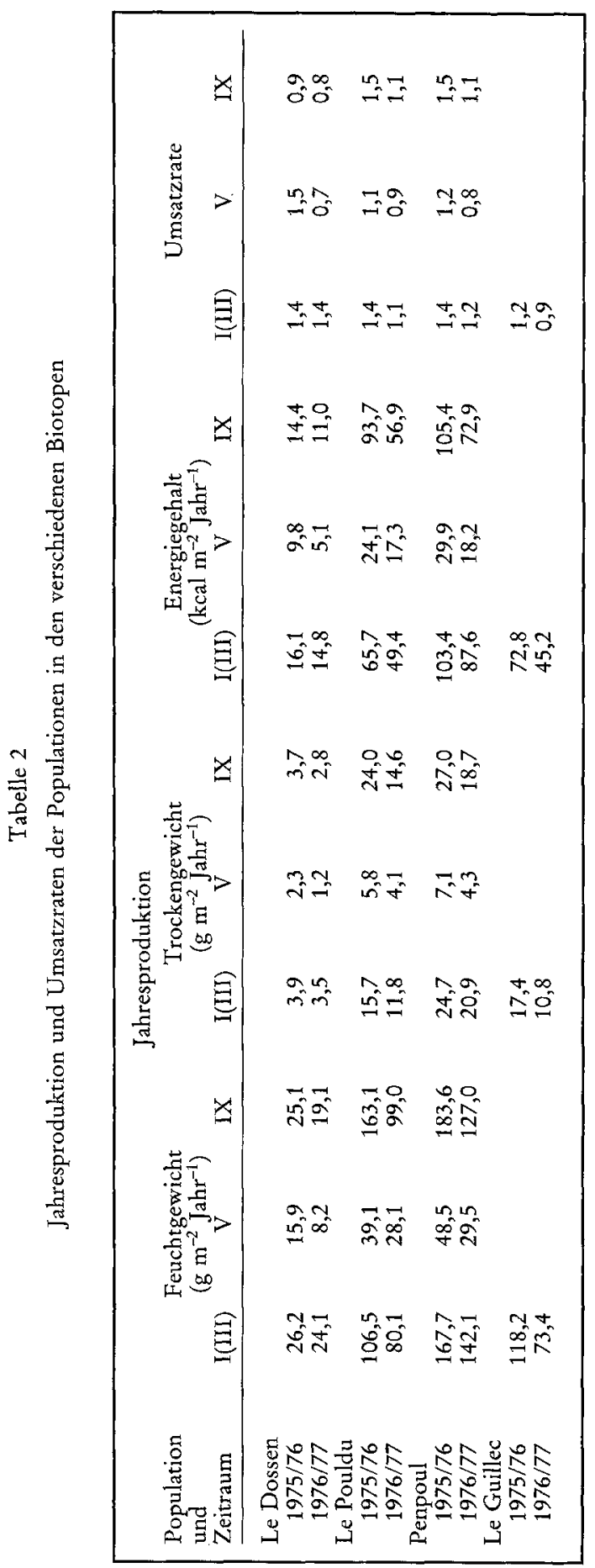


Bombe-Calorimeters an 10 großen $(5$ bis $10 \mathrm{~g})$ und 50 kleinen $(0,5$ bis $2 \mathrm{~g})$ Würmern vorgenommen. Der mittlere physiologische Brennwert der großen Tiere war mit $4193 \mathrm{cal} /$ g Trockensubstanz etwas größer als der der kleinen Tiere mit 3906 cal. Der Unterschied läßt vermuten, daß die großen Würmer mehr energiereiche Reservestoffe aufgebaut haben als die kleineren.

\section{Energieverluste durch Stoffwechselleistungen}

Der für Stoffwechselleistungen aufgewandte Energiebetrag wird gewöhnlich anhand der Respirationsgröße ermittelt. Bei der Mehrzahl der Tiere einschließlich A. marina nimmt im Verlauf des Wachstums der Sauerstoffverbrauch je Gewichtseinheit ab. Der mathematische Weg, dies auszudrücken, ist in der allometrischen Formel gegeben: $\mathrm{y}=\mathrm{b} \cdot \mathrm{w}^{\mathrm{a}} \quad\left(\mathrm{y}=\mathrm{O}_{2}\right.$-Verbrauch in $\mathrm{mm}^{3} / \mathrm{h} ; \mathrm{b}=\mathrm{O}_{2}$-Verbrauch $/ \mathrm{g}$ Körpersubstanz; $\mathrm{w}=$ Gewicht; $\mathrm{a}=$ allometrischer Exponent).

Die Temperaturabhängigkeit des Sauerstoffverbrauchs von $A$. marina ist durch Unstetigkeiten charakterisiert, worunter Temperaturbereiche verstanden werden, in denen der Anstieg des Sauerstoffverbrauchs geringer ist, als es die RGT-Regel erwarten läßt. Aus diesen Unstetigkeiten ergibt sich, daß die Atmungsgröße der Würmer in dem Bereich zwischen 10 und $20^{\circ} \mathrm{C}$ nur in geringem Maße temperaturabhängig ist (Krüger, 1964). Da die mittlere Luft- und Wassertemperatur bei Roscoff nur zwischen 8 und $17^{\circ} \mathrm{C}$ schwankt, wird den Berechnungen für die Wintermonate November bis April eine mittlere Temperatur von $10^{\circ} \mathrm{C}$, den Sommermonaten Mai bis Oktober eine solche von $15{ }^{\circ} \mathrm{C}$ zugrunde gelegt. Krüger (1964) gibt für die Parameter b und a bei $10 \mathrm{bzw} .15^{\circ} \mathrm{C}$ die Durchschnittswerte von 39,2 und 0,82 bzw. 64,1 und 0,72 an.

Unter der Berücksichtigung, daß ein Monat durchschnittlich 732 Stunden hat, ergibt sich rechnerisch der jährliche Sauerstoffverbrauch der Population nach den Formeln:

$$
\begin{aligned}
& \mathrm{R}_{\mathrm{j}}\left(\mathrm{cm}^{3}\right)=\mathrm{R}_{\text {Nov.-Apr. }}+\mathrm{R}_{\text {Mai-Okt. }} \\
& \mathrm{R}_{\text {Nov.-Apr. }}=\sum_{\text {Apr. }}^{\text {Nov. }} \mathbf{N} \cdot \mathbf{w}^{-0,82} \cdot 39,2 \cdot 0,732 \\
& \mathrm{R}_{\text {Mai-Okt. }}=\sum_{\text {Okt. }}^{\text {Mai }} \cdot \mathbf{w}^{-0,72} \cdot 64,1 \cdot 0,732
\end{aligned}
$$

Die Daten des Sauerstoffverbrauchs der Teilpopulationen auf den unterschiedlichen Höhenniveaus sowie deren Energieäquivalente sind in Tabelle 3 zusammengefaßt.

\section{Energieabgaben durch Exkremente}

Aquarienversuche zeigten, daß keine signifikanten Unterschiede in der Kotproduktion zwischen Ebbe und Flut bestehen. Auch Tauchuntersuchungen, die im Sommer 1976 an den Untersuchungsstationen der Biotope durchgeführt wurden, ließen keinen Einfluß der Tiden auf die Kotabgabe erkennen. 
Tabelle 3

Respirationsraten und deren Energieäquivalente der Populationen in den verschiedenerr Biotopen

\begin{tabular}{|c|c|c|c|c|c|c|}
\hline \multirow{2}{*}{$\begin{array}{l}\text { Population } \\
\text { und } \\
\text { Zeitraum }\end{array}$} & \multicolumn{3}{|c|}{$\begin{array}{l}\text { Respiration } \\
\left(\mathrm{O}_{2} \mathrm{ml} \mathrm{Jahr}^{-1}\right)\end{array}$} & \multicolumn{3}{|c|}{$\begin{array}{c}\text { Energieäquivalent } \\
\left(\mathrm{kcal} \mathrm{Jahr}^{-1}\right)\end{array}$} \\
\hline & I (III) & $\mathrm{V}$ & IX & I (III) & $\mathrm{V}$ & IX \\
\hline \multicolumn{7}{|l|}{ Le Dossen } \\
\hline $1975 / 76$ & 5601 & 3252 & 14308 & 27 & 16 & 69 \\
\hline $1976 / 77$ & 5183 & 3369 & 12777 & 25 & 16 & 61 \\
\hline \multicolumn{7}{|l|}{ Le Pouldu } \\
\hline $19-5 / 76$ & 29855 & 14054 & 56498 & 143 & 67 & 271 \\
\hline $1976 / 77$ & 27033 & 13852 & 43114 & 130 & 66 & 207 \\
\hline \multicolumn{7}{|l|}{ Penpoul } \\
\hline $1975 / 76$ & 34577 & 14577 & 56434 & 166 & 70 & 271 \\
\hline $1976 / 77$ & 34996 & 12966 & 54220 & 168 & 62 & 260 \\
\hline \multicolumn{7}{|l|}{ Le Guillec } \\
\hline $1975 / 76$ & 32495 & & & 156 & & \\
\hline $1976 / 77$ & 28658 & & & 138 & & \\
\hline
\end{tabular}

Tabelle 4

Mittlere Kotabgabe je Gewichts- und Zeiteinheit sowie je Flächen- und Zeiteinheit und Energiegehalt des abgegebenen Kotsandes

\begin{tabular}{|c|c|c|c|c|c|c|c|c|c|c|c|}
\hline \multirow{3}{*}{ Probenort } & & \multicolumn{10}{|c|}{ Mittlere Kotabgabe } \\
\hline & & \multicolumn{4}{|c|}{ je Gramm Wurmgewicht } & \multicolumn{3}{|c|}{ je $\mathrm{m}^{2}$ und Tag } & \multicolumn{3}{|c|}{ je $\mathrm{m}^{2}$ und Jahr } \\
\hline & & Jan. & Apr. & Juli & Okt. & Jan. & Apr. & Juli & Okt. & $\mathrm{kg}$ & $\mathrm{kcal}$ \\
\hline \multirow[t]{3}{*}{ Le Dossen } & I & 1,8 & 2,4 & 2,7 & 2,4 & 19 & 39 & 69 & 45 & 16 & 496 \\
\hline & V & 1,9 & 2,3 & 3,1 & 2,3 & 11 & 19 & 44 & 43 & 11 & 244 \\
\hline & IX & 4,4 & 4,8 & 4,9 & 4,6 & 103 & 85 & 130 & 182 & 45 & 1090 \\
\hline \multirow{3}{*}{ Le Pouldu } & III & 1,7 & 2,2 & 2,1 & 2,2 & 54 & 160 & 266 & 215 & 63 & 1791 \\
\hline & $\mathrm{V}$ & 2,0 & 2,1 & 2,2 & 1,9 & 30 & 79 & 104 & 106 & 29 & 597 \\
\hline & IX & 6,4 & 10,5 & 7,3 & 5,3 & 604 & 1051 & 1057 & 737 & 314 & 5836 \\
\hline \multirow[t]{3}{*}{ Penpoul } & I & 1,7 & 2,4 & 2,0 & 2,2 & 227 & 202 & 256 & 296 & 89 & 2284 \\
\hline & $\mathrm{V}$ & 2,4 & 2,9 & 2,9 & 2,7 & 68 & 78 & 122 & 151 & 38 & 2309 \\
\hline & IX & 6,3 & 8,9 & 10,2 & 5,9 & 875 & 1327 & 926 & 681 & 347 & 10398 \\
\hline Le Guillec & III & 4,0 & $\begin{array}{l}0,7 \\
3,7\end{array}$ & 4,8 & 2,8 & 319 & 257 & 461 & 404 & 131 & 3081 \\
\hline
\end{tabular}

Die Ergebnisse der Untersuchungen sind in Tabelle 4 dargestellt. Die Menge des abgegebenen Kotes je Zeiteinheit war grundsätzlich abhängig von der Körpergröße. Jedoch stieg sie nicht linear, sondern nahm im Verlauf des Wachstums je Gewichtseinheit ab. Da die mittlere Körpergröße der Tiere mit abnehmendem Niveau zunahm, war auch die Kotproduktion je Gramm Biomasse im oberen Gezeitenbereich stets am größten und nahm mit abnehmendem Niveau ab.

Die Kotabgabe je Gewichtseinheit war im unteren und mittleren Abschnitt der drei Untersuchungsgebiete etwa gleich groß. Im oberen Abschnitt war sie hingegen im Watt von Le Dossen deutlich kleiner als an den anderen Biotopen.

Während der Herbst- und Wintermonate Oktober und Januar war die Kotproduktion 
etwas geringer als im Frühling und Sommer, und zwar bei Le Dossen um 8 bis 22, Le Pouldu um 9 bis 34, Penpoul um 12 bis 36 und Le Guillec um $20 \%$.

In Tabelle 4 sind weiterhin die berechneten Werte für die Kotproduktion je Quadratmeter und Tag sowie je Quadratmeter und Jahr für die verschiedenen Biotope und Wattabschnitte angegeben. Die höchsten Werte wurden für den Port de Penpoul ermittelt, wo 1976 im unteren, mittleren und oberen Bereich 89,2, 38,1 und 346,6 kg Kotsand abgegeben wurden. Das entspricht etwa einem Volumen von 59,7, 25,9 und 215,7 l, und würde die ausgeschiedene Kotmenge über einem Quadratmeter ausgebreitet, einer Sedimenthöhe von 5,9,2,6 und 21,5 cm. Die entsprechenden Werte lauten für Le Pouldu 63,3, 29,0 und $313,8 \mathrm{~kg}$ bzw. 45,8, 18,8 und 201,71 bzw. 4,6, 1,9 und 20,2 cm, für Le Dossen $15,7,10,8$ und $45,4 \mathrm{~kg}$ bzw. 12,3, 8,5 und $41,4 \mathrm{lbzw} .1,2,0,9$ und 4,1 cm und für Le Guillec $131,1 \mathrm{~kg}$ bzw. 103,91 bzw. $10,4 \mathrm{~cm}$. In Tabelle 4 ist weiterhin der Energiegehalt der Exkremente angegeben.

\section{Assimilation, Konsumption und ökologische Effizienz}

In Tabelle 5 sind die Werte der Assimilation, Konsumption, Assimilations-, Produktions- und Aufbaueffizienz zusammengefaßt. Sowohl die Assimilation als auch die Konsumption je Flächeneinheit waren stets im oberen Wattbereich am größten; sie nahmen mit sinkendem Niveau im mittleren Bereich stark ab und im unteren Bereich wieder zu. Der Assimilations- und Konsumptionsunterschied zwischen dem oberen und unteren bzw. mittleren Niveau war relativ größer als der Produktionsunterschied, weil die kleinen Tiere, die im oberen Hang konzentriert sind, größere Respirations- und Defäkationswerte aufwiesen als die mittleren und großen Tiere. Assimilation und Konsumption waren 1976/77 1 bis $19 \%$ geringer als $1975 / 76$.

Die Assimilationseffizienz (assimilation efficiency) gibt an, welcher Teil der aufgenommenen Nahrungsenergie wirklich für den Aufbau tierischer Substanz und Aufrechterhaltung des Betriebsstoffwechsels genutzt wird. Sie war im oberen Gezeitenbereich generell kleiner als im mittleren und unteren. Im Durchschnitt wurden im oberen Abschnitt 5,0, im mittleren 8,4, im unteren 9,2\% und, bezogen auf das ganze Wattprofil, $7,4 \%$ der konsumierten Energie assimiliert.

Die Produktionseffizienz (gross growth efficiency, ecological growth efficiency) gibt an, welcher Anteil der aufgenommenen Energie zur Produktion von Körpergewebe und Nachkommen verbraucht wird. Sie wies ebenfalls im oberen Hang kleinere Werte auf als im mittleren und unteren Wattbereich. Im Durchschnitt wurden im oberen Abschnitt 1,0, im mittleren 2,3, im unteren 3,2\% und, bezogen auf das ganze Profil, 2,1\% der aufgenommenen Nahrungsenergie in körpereigene Substanz umgebaut.

Die Aufbaueffizienz (net growth efficiency, tissue growth efficiency) gibt an, wieviel von der assimilierten Energie für den Aufbau der tierischen Substanz verwendet wird. Sie war im oberen Hang mit durchschnittlich 21,6\% am geringsten und nahm über den mittleren Bereich mit $27 \%$ bis zum unteren Bereich mit 34,4\% zu. Es zeigte sich hier, daß die kleinen Tiere einen relativ größeren Anteil der aufgenommenen Energie für Respirationsleistungen verbrauchen als die größeren. Mit fallendem Niveau nahm das mittlere Körpergewicht der Tiere zu und der, für Respiration verwandte Anteil der assimilierten Energie ab. 
Energiehaushalt des Wattwurms

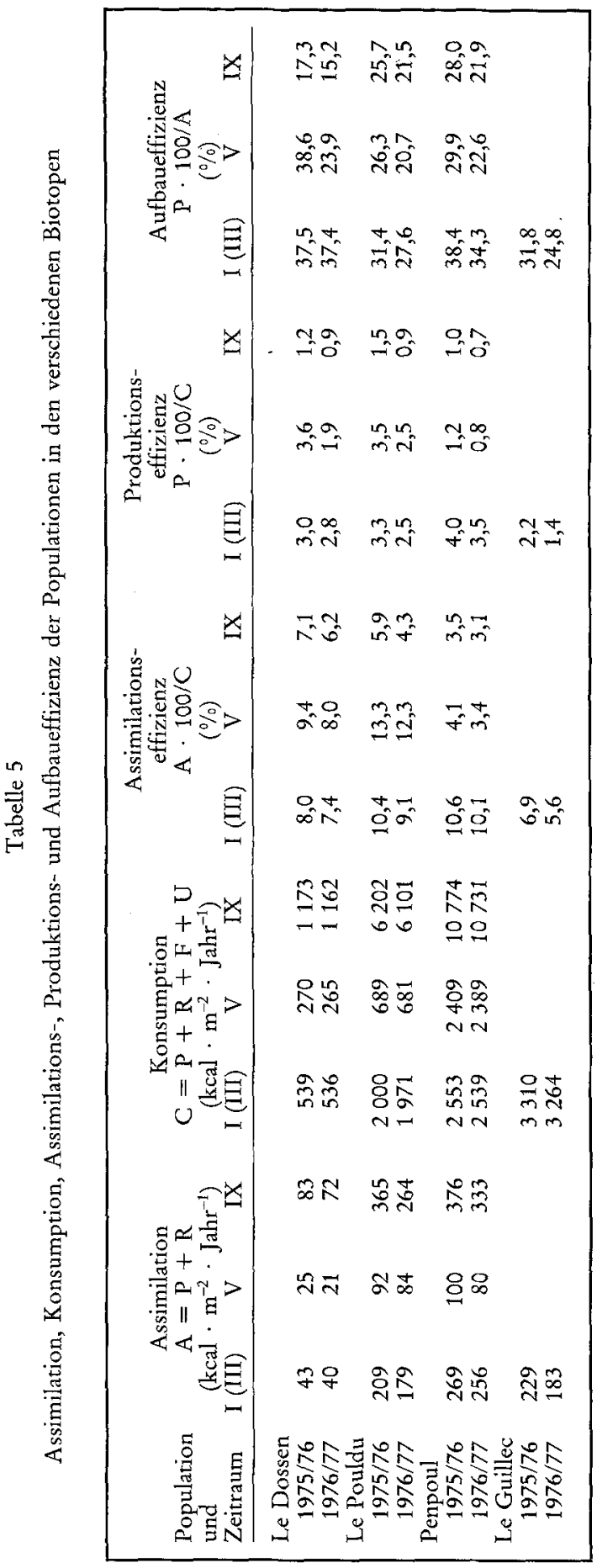




\section{Entwicklung der Geschlechtszellen}

Arenicola marina ist getrenntgeschlechtlich. Die Gonaden liegen am unteren Rande des Trichters der Nephridien. Sie bestehen aus sehr kleinen Zellmassen von etwa 0,5 bis $1 \mathrm{~mm}$ Durchmesser. Die Geschlechtszellen fallen in frühen Entwicklungsstadien in die Leibeshöhle, wo sie sich anhäufen und ihr weiteres Wachstum durchmachen. Die Spermien entwickeln sich angeheftet an eine Nährzelle, die sie wie die Haare einer Bürste umgeben. Die Eizellen vollziehen ihre Reifung isoliert. Die Geschlechtszellen verlassen die Leibeshöhle durch die Nephridien (Zusammenfassung bei Krüger, 1971).

\section{Eizelle}

Die Oocyten werden ins Coelom abgestoßen, wenn sie einen Durchmesser von etwa $12 \mu \mathrm{m}$ haben. Diese Frühstadien wurden das ganze Jahr über in der Leibeshöhlenflüssigkeit gefunden und traten ab Februar in größerer Anzahl auf. Sie bestehen aus kugelrunden, farblosen Bläschen, die neben dem deutlich sichtbaren Zellkern noch 1 bis 5 stark lichtbrechende Granulae von $1 \mu \mathrm{m}$ Durchmesser enthalten. Während der Frühjahrsmonate wuchsen die Oocyten langsam, bis sie etwa 40 bis $50 \mu \mathrm{m}$ groß waren. Sie hatten jetzt eine mehr oder weniger abgeplattete, ovale oder eiförmige Gestalt. Das Plasma enthielt wesentlich mehr granuläre gelblich-braune Einschlüsse, jedoch war der Zellkern noch deutlich zu erkennen. Es folgte eine Phase schnelleren Wachstums, die, sobald die Zellen einen Durchmesser von 150 bis $160 \mu \mathrm{m}$ erreicht hatten, wieder in langsameres Wachstum überging (Abb. 13). Inzwischen hatte die sich jetzt kugelrunde Zelle weiterhin mit dunkelbraunem Dottermaterial angefüllt, so daß der Zellkern nur noch undeutlich in der Mitte des Eies als etwa $10 \mu \mathrm{m}$ großes, kreisrundes, helleres Zentrum zu erkennen war, und eine dicke Eihülle wurde ausgebildet. Die ausgewachsenen Oocyten hatten eine planoconvexe Gestalt, mit einem größeren Durchmesser von 180 bis $185 \mu \mathrm{m}$ und einem kleineren von 120 bis $130 \mu \mathrm{m}$. Die Oberfläche war oft mit einer weiten, flachen Vertiefung von etwa $90 \mu \mathrm{m}$ Durchmesser und $20 \mu \mathrm{m}$ Tiefe versehen. Das Dottermaterial war jetzt aufgelockert, hellbraun und ließ den Kern deutlich als klares, kreisrundes Zentrum von etwa $60 \mu \mathrm{m}$ Durchmesser erkennen.

Während der Phase des schnelleren Wachstums wurden in einem Tier noch alle frühen Entwicklungsstadien, besonders kleine Eier bis zu $100 \mu \mathrm{m}$ Durchmesser, gefunden. Je weiter die Entwicklung fortschritt, desto mehr verschob sich das Gleichgewicht zu den späteren Stadien, und in reifen Tieren waren gewöhnlich fast nur noch voll ausgewachsene Eizellen von 180 bis $185 \mu \mathrm{m}$ Größe zu finden.

Während die Oocyten der Würmer aller Wattgebiete und Untersuchungsstationen gleichermaßen die oben beschriebenen Erscheinungsbilder aufwiesen, waren Unterschiede in der Entwicklungsgeschwindigkeit in den verschiedenen Biotopen und sogar an verschiedenen Höhenniveaus des gleichen Biotops feststellbar. Die Ergebnisse der regelmäßigen Untersuchungen zur Größenzunahme der Oocyten in der Zeit von Februar bis Dezember 1976 sind in der Abbildung 14 graphisch dargestellt. Die Werte des mittleren OocytenDurchmessers wurden aus den Querschnitten der am weitesten entwickelten OocytenStadien von mindestens 30 Würmern je Untersuchungsstation und Monat errechnet. Es 
zeigte sich, daß an den Probenorten I bis V die Oocyten der Würmer von Penpoul am frühesten ihre volle Größe erreichten, nämlich bereits im August (Probenort I) bis September (Probenorte III und V). Es folgt Le Dossen, wo die maximale Größe im September (Probenort I) bis Oktober (Probenorte III und V) erreicht wurde, und schließlich Le Pouldu mit entsprechenden Werten im November (Probenorte I bis V). Am Probenort VII erreichten hingegen die Oocyten der Würmer von Le Dossen Ende Oktober und damit am frühesten ihre ausgewachsene Größe, während die der Würmer von Le Pouldu und Penpoul bis zum Ablaichtermin im November weiterwuchsen.

Beim Betrachten der oben beschriebenen drei Abschnitte der Wachstumskurven fällt auf, daß die Phase der anfänglich langsamen Größenzunahme im stark-lotischen Watt von Le Dossen zeitlich am längsten verlief, gefolgt von der der mittel- und schwach-lotischen Gebiete von Le Pouldu und Penpoul. Die sich anschließende Phase schnellen Wachstums dauerte hingegen bei Le Dossen die kürzeste Zeit, gefolgt von der von Penpoul und Le Pouldu.
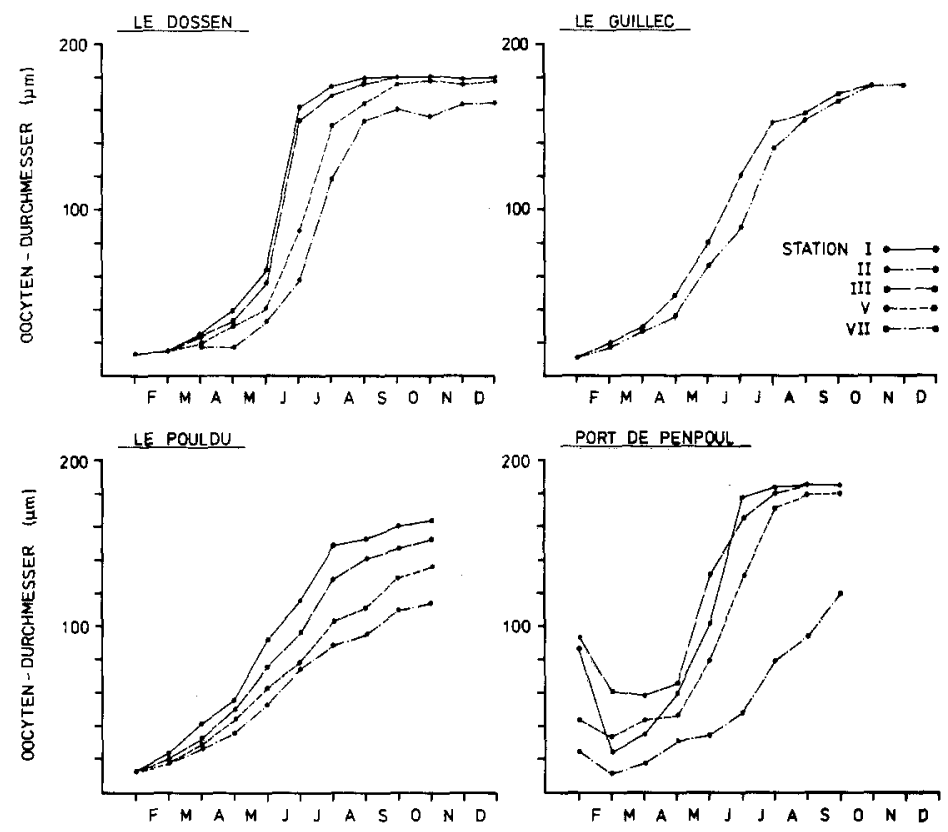

Abb. 14: Größenentwicklung der Eizellen in den untersuchten Biotopen in Abhängigkeit vom Höhenniveau der Untersuchungsstation

Abbildung 14 zeigt weiterhin, daß sowohl die Phase der anfänglich langsamen als auch besonders die der folgenden schnellen Größenzunahme jeweils an der Untersuchungsstation I des Biotops die kürzeste Zeit dauert und mit steigendem Niveau länger wird. So war bei Le Dossen die Phase langsamen Wachstums am Probenort I bereits Mitte Mai, am Probenort VII dagegen erst Mitte Juni abgeschlossen. Bei Le Pouldu liegen die entsprechenden Werte zwischen Anfang und Ende April und bei Penpoul zwischen Anfang April und Ende Juni. Die Phase des schnelleren Wachstums erstreckte sich bei Le Dossen über 
11/2 (Probenort I) bis 2 Monate (Probenort VII), bei Le Pouldu über 4 (Probenort I) bis 5 Monate (Probenort VII) und bei Penpoul über 21/2 (Probenort I) bis 3 Monate (Probenort VII).

An den Untersuchungsstationen von Le Guillec, welche mit den Probenorten VIII der anderen Biotope auf gleichem Höhenniveau liegen, verlief die Größenentwicklung der Oocyten wie bei Le Dossen VII. Jedoch war hier die anfängliche Phase des langsamen Wachstums kürzer.

Die Wachstumskurven für die Probenorte des Port de Penpoul zeigen für den Monat Februar zunächst eine Abnahme des mittleren Oocytendurchmessers an. Hier wurden Anfang Februar an allen Untersuchungsstationen einige Würmer mit voll entwickelten Oocyten gefunden. An den Probenorten I bis V wurden in geringerem Maße auch im März noch reife Oocyten festgestellt. Im April traten hingegen nur noch Frühstadien auf. Es kann nicht mit Sicherheit gesagt werden, daß die reifen Eizellen im März abgegeben und befruchtet worden sind. Im darauffolgenden Frühjahr wurden trotz ausgedehnter Untersuchungen keine reifen Oocyten gefunden.

\section{Spermienplatte}

Die männlichen Geschlechtszellen lösen sich bereits als Spermatogonien von den Gonaden. Es werden immer gleichzeitig mehrere Spermatogonien abgegeben, die durch einen sogenannten Blastophor (Ashworth, 1904) miteinander verbunden sind. Sie bestehen aus 4 bis 8 Zellen, und ihr Durchmesser beträgt mindestens $20 \mu \mathrm{m}$. Diese Frühstadien wurden das ganze Jahr über in geringer Anzahl in der Coelomflüssigkeit gefunden. In den Frühjahrsmonaten ab Februar traten sie in größeren Mengen auf. Die Spermatogonien teilten sich in der Folgezeit recht häufig und bildeten schließlich bis zu $50 \mu \mathrm{m}$ große Spermatocystenkugeln, die einer Morula ähnelten und über 100 Zellen enthielten. Mit der Umwandlung der Spermatocysten in Spermatiden flachten sich die kugelrunden Gebilde $\mathrm{ab}$ und bildeten schließlich flache Tafeln. Die flachen, runden Plättchen waren bis zu $100 \mu \mathrm{m}$ groß und enthielten mehrere hundert Spermatiden. Während der nun folgenden Spermiohistogenese entstanden die langgeschwänzten Spermien, die jedoch noch mit den Köpfen am Blastophor angeheftet waren. Die Spermienplatten wurden dabei durchschnittlich etwas kleiner. Die Spermien blieben zunächst unbeweglich. Erst später, kurz vor dem Laichtermin, begannen einige Spermiengeißeln zu schlagen, wodurch die Spermienplatten oftmals in eine Drehbewegung gerieten. Die Spermien haben sich wohl erst unmittelbar vor dem Laichakt aus den Platten gelöst.

Die Entwicklung der Spermienplatten kann ähnlich wie die der Eizellen in drei Phasen unterteilt werden (Abb. 15). Während der Frühjahrsmonate wuchsen die Spermatogonienkugeln langsam, bis sie etwa 40 bis $45 \mu \mathrm{m}$ groß waren. In der folgenden Phase, während der sich die Spermatocysten in Spermatiden umwandelten, vergrößerten sich die Verbände schnell durch Teilung auf den doppelten Umfang. Anschließend blieben die Spermienplatten bis zur Abgabe der Geschlechtsprodukte in Form und Größe unverändert.

An den Probenorten I und III der Untersuchungsgebiete erreichten die Spermienplatten der Würmer von Penpoul am frühesten, nämlich schon im August, ihre volle Größe. Es folgten die der Würmer von Le Dossen und Le Pouldu Anfang und Ende September. An 
den Probenorten V und VII waren hingegen die Spermienplatten der Würmer von Le Dossen am frühesten ausgewachsen (Ende September), während die der Würmer von Le Pouldu bis zum Ablaichtermin im November weiterwuchsen (Abb. 15).
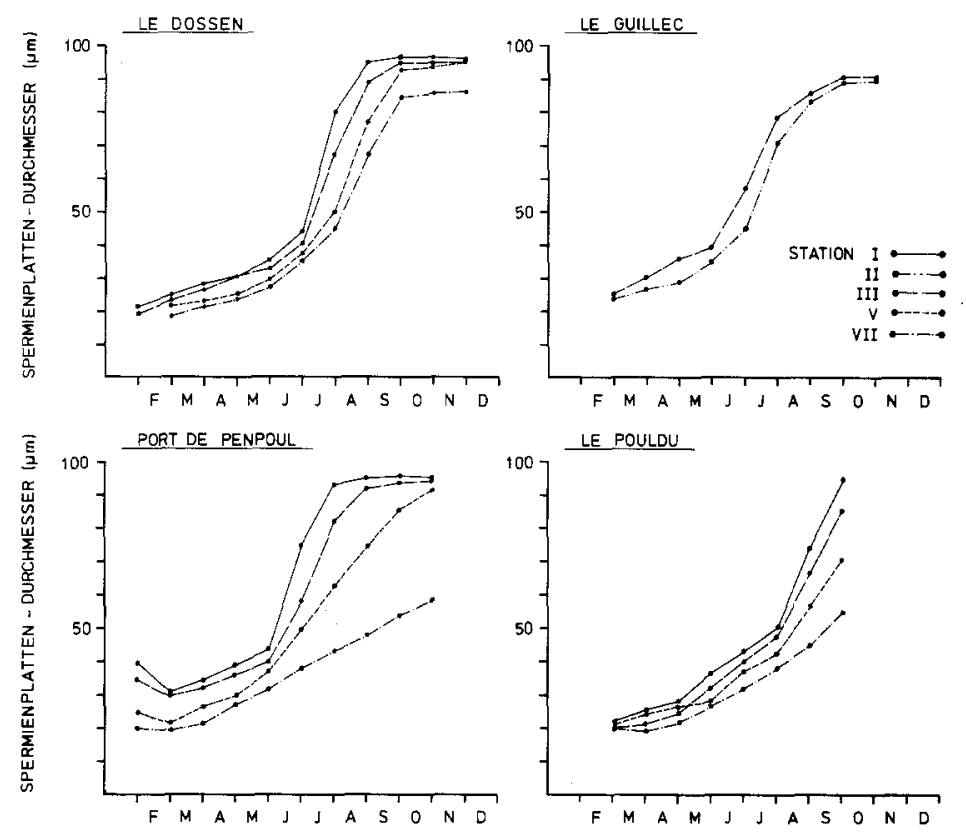

Abb. 15: Größenentwicklung der Spermienplatten in den untersuchten Biotopen in Abhängigkeit vom Höhenniveau der Untersuchungsstation

Die Phase der anfänglichen langsamen Größenzunahme war auf allen Höhenniveaus bei Penpoul am kürzesten und ging hier Anfang Juni in die Phase schnelleren Wachstums über. Bei Le Dossen war sie an den Probenorten I und III im Juni, an den Probenorten V und VII im Juli und bei Le Pouldu an allen Probenorten ebenfalls im Juli beendet. Die Phase des schnellen Wachstums dauerte bei Le Dossen an allen Probenorten die kürzeste Zeit, nämlich 2 bis $2 \frac{1}{2}$ Monate. Bei Penpoul erstreckte sie sich an den Probenorten I und III über $2 \frac{1}{2}$ Monate, an den Probenorten V und VII über 4 Monate, bis zur Abgabe der Geschlechtsprodukte. Bei Le Pouldu dauerte sie schließlich an den Probenorten I bis V 2 Monate lang und erstreckte sich hier ebenfalls bis zum Ablaichtermin.

Aus den Darstellungen des Wachstums der Spermienplatten in Abhängigkeit vom Höhenniveau der Untersuchungsstationen (Abb. 15) ist ersichtlich, daß hier, wie bei der Entwicklung der Eizelle, die Phase der schnellen Größenzunahme an allen Biotopen jeweils an der Untersuchungsstation I die kürzeste Zeit dauerte und mit steigendem Höhenniveau länger wurde.

Die Entwicklung der Spermienplatten der Würmer von Le Guillec verlief, was die Länge der Phasen angeht, wie die der Tiere von Le Dossen an der Untersuchungsstation VII. Jedoch wurden hier die Spermienplatten um durchschnittlich $5 \mu \mathrm{m}$ größer. 
Die Wachstumskurven für die Probenorte I bis V des Port de Penpoul zeigen im Februar zunächst eine Abnahme des mittleren Spermienplattendurchmessers an. Es wurden hier Anfang Februar und in geringerem Maße Anfang März einige Würmer mit ausgewachsenen und in Spermien differenzierten Platten gefunden. Im April waren hingegen nur noch kleine Spermatogonien festzustellen. Im darauffolgenden Frühjahr 1977 wurden trotz ausgedehnter Nachforschungen keine reifen Geschlechtsprodukte gefunden.

\section{Anteile der Geschlechter und Abgabe der Geschlechtsprodukte}

Während die Tiere bei Whitstable (Newell, 1948), Texel (Vooys, 1975) und Arcachon (Cazaux, 1966) erst ab Mai oder Juni Geschlechtszellen in der Coelomflüssigkeit aufwiesen, waren solche bei Roscoff in allen vier Biotopen das ganze Jahr über wenigstens in einigen Individuen zu finden, so daß das Geschlechterverhältnis auch während der kälteren Monate verfolgt werden konnte.
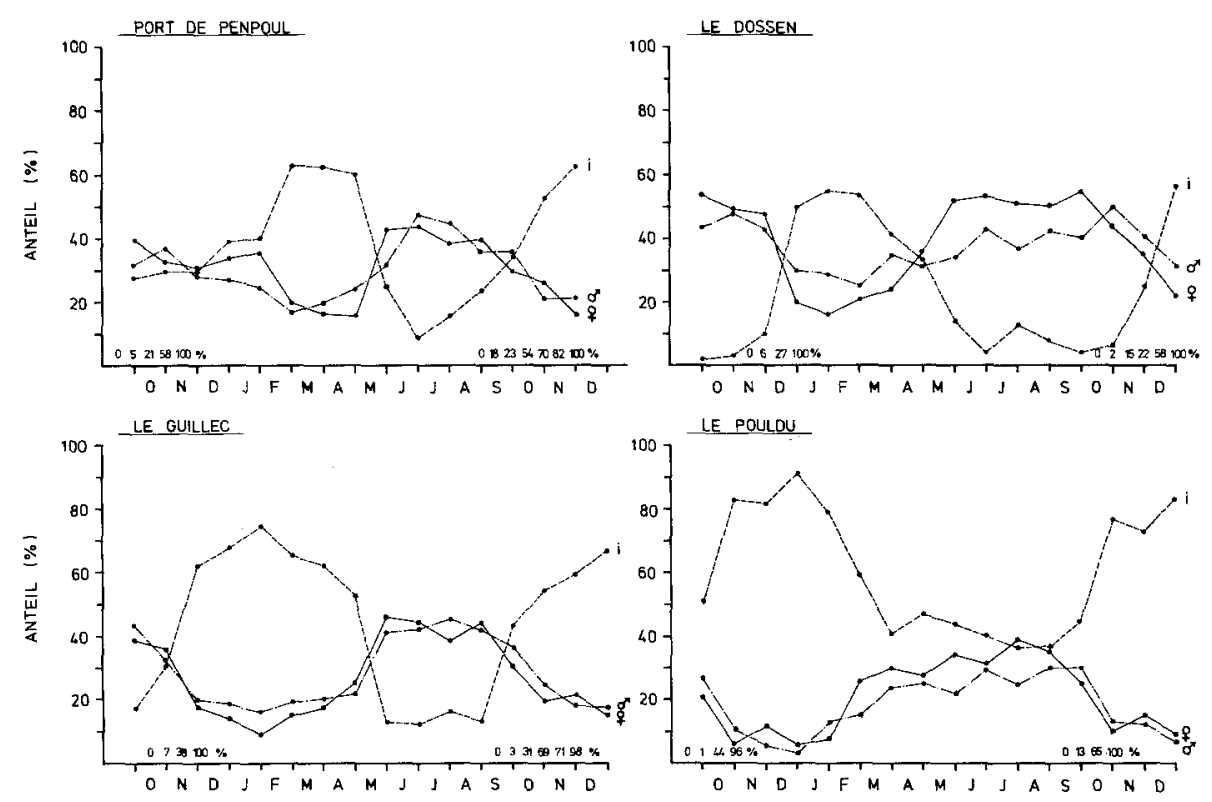

Abb. 16: Prozentualer Anteil der Weibchen, Männchen und indifferenten Tiere (i) an der Gesamtpopulation. Uber der Abzisse ist der Anteil der Tiere, die bereits abgelaicht haben, angegeben

Während der Wintermonate enthielten bei Le Dossen mindestens 44, Le Pouldu 10, Penpoul 36 und Le Guillec $26 \%$ der adulten Würmer Frühstadien von Geschlechtszellen in der Coelomflüssigkeit. Ab März, bei Le Pouldu schon ab Januar, stiegen die Werte und erreichten Anfang Juli (Le Dossen, Le Guillec, Penpoul) und Anfang August (Le Pouldu) ihre Maxima. Im Sommer wiesen bei Le Dossen höchstens 96, Le Pouldu 61, Penpoul 91 und Le Guillec $87 \%$ der Tiere Geschlechtszellen auf. Mit Eintritt der Ablaichperiode, 
nämlich bei Le Dossen ab November, Le Pouldu ab Oktober, Penpoul und Le Guillec ab September sank die Zahl der geschlechtlich unterscheidbaren Tiere wieder (Abb. 16). Bei vielen Individuen war aber auch nach dem Ablaichen noch das Geschlecht zu erkennen, weil entweder schon wieder Frühstadien gebildet worden waren oder wenige reife Geschlechtszellen in der Leibeshöhle zurückgeblieben waren. Diese waren dann aber, im Vergleich zu den normalen Geschlechtszellen, etwas kleiner oder deformiert.

Das Verhältnis der Geschlechter zueinander liegt bei Le Guillec und Penpoul das ganze Jahr über etwa bei 1:1. Bei Le Dossen und Le Pouldu waren hingegen im Sommer die weiblichen Tiere in der Uberzahl. Bei Le Dossen wurden darüber hinaus im Winter durchschnittlich $27 \%$ mehr männliche als weibliche Tiere gefunden.

Der prozentuale Anteil der vollständig oder teilweise abgelaichten Würmer ist in der Abbildung 15 über der Abzisse angegeben. Die Abgabe der Geschlechtszellen erfolgte sowohl 1975 als auch 1976 an den verschiedenen Biotopen zu verschiedenen Zeiten und dauerte unterschiedlich lange. Sie erstreckte sich 1975 bei Penpoul von Anfang Oktober bis Ende November (2 Monate), bei Le Pouldu von Anfang bis Ende Oktober (1 Monat), bei Le Guillec von Anfang bis Ende November (1 Monat) und bei Le Dossen von Anfang bis Ende Dezember (1 Monat). 1976 setzte die Ablaichperiode an allen Biotopen früher ein, dauerte aber länger und schloß dann etwa zum gleichen Zeitpunkt ab wie im vorangegangenen Jahr. So dauerte sie bei Penpoul von Anfang September bis Ende November (3 Monate), bei Le Pouldu von Mitte September bis Ende Oktober ( $1 \frac{1 / 2}{2}$ Monate), bei Le Guillec von Anfang Oktober bis Ende November (2 Monate) und bei Le Dossen von Anfang November bis Ende Dezember (2 Monate).

Tabelle 6

Prozentualer Anteil der Würmer mit voll ausgebildeten Geschlechtsprodukten in Abhängigkeit vom Körpergewicht. Die Untersuchungen wurden kurz vor dem Ablaichen im Herbst 1976 durchgeführt

\begin{tabular}{|ccccc|}
\hline $\begin{array}{c}\text { Gewichtsgruppe } \\
(\mathrm{g})\end{array}$ & Le Dossen & Le Pouldu & Penpoul & Le Guillec \\
\hline $0-1,35$ & 0 & 1 & 0 & 0 \\
$1,36-1,8$ & 0 & 2 & 4 & 0 \\
$1,81-2,4$ & 0 & 16 & 12 & 0 \\
$2,41-3,2$ & 8 & 35 & 33 & 5 \\
$3,21-4,25$ & 46 & 65 & 71 & 49 \\
$4,26-5,7$ & 63 & 83 & 70 & 79 \\
$5,71-7,5$ & 89 & 94 & 95 & 64 \\
$7,51-10,0$ & 81 & 96 & 90 & 94 \\
$10,01-13,5$ & 98 & - & 92 & 100 \\
$13,51-18,0$ & 95 & - & 100 & - \\
$18,01-24,0$ & 100 & - & 100 & - \\
$>24,01$ & 100 & - & 100 & \\
\hline
\end{tabular}

\section{Größe und Alter der geschlechtsreifen Tiere}

Die Tabelle 6 zeigt den prozentualen Anteil der Tiere mit vollausgebildeten Geschlechtszellen in Abhängigkeit vom Körpergewicht. Hiernach waren die Würmer von 
Le Pouldu und Penpoul bei Eintritt in die Geschlechtsreife durchschnittich etwas kleiner als die von Le Dossen und Le Guillec. Der kleinste fortpflanzungsfähige Wurm war $0,9 \mathrm{~g}$ schwer und wurde bei Le Pouldu IX gefunden. Allerdings waren dieser und auch die anderen kleinen reifen Würmer bereits wie die größeren Artgenossen dunkel- bis schwarzbraun gefärbt, wohingegen die jungen, indifferenten Tiere rötlich bis rotbraun sind. Ein Vergleich mit den Größengruppendiagrammen zeigt, daß die Tiere, die erstmals geschlechtsreif wurden und ein Gewicht ab etwa $3 \mathrm{~g}$ (Le Dossen und Le Guillec) bzw. $2 \mathrm{~g}$ (Le Pouldu und Penpoul) hatten, mindestens 2 Jahre alt waren. Es befanden sich jedoch auch unter den größeren Würmern immer einige, die nur unterentwickelte, unreife Geschlechtszellen ausbildeten. Es ist anzunehmen, daß diese frühestens im dritten Lebensjahr fortpflanzungsfähig wurden oder aber steril blieben.

\section{Natalität und Fertilität}

Es zeigte sich, daß, ungeachtet der Körpergröße und Herkunft, die gleiche Menge Coelomflüssigkeit etwa die gleiche Anzahl ausgewachsener Eier enthielt. Die potentielle Natalität ist also proportional dem Körpergewicht, und zwar enthalten 0,1 g Coelomflüs-

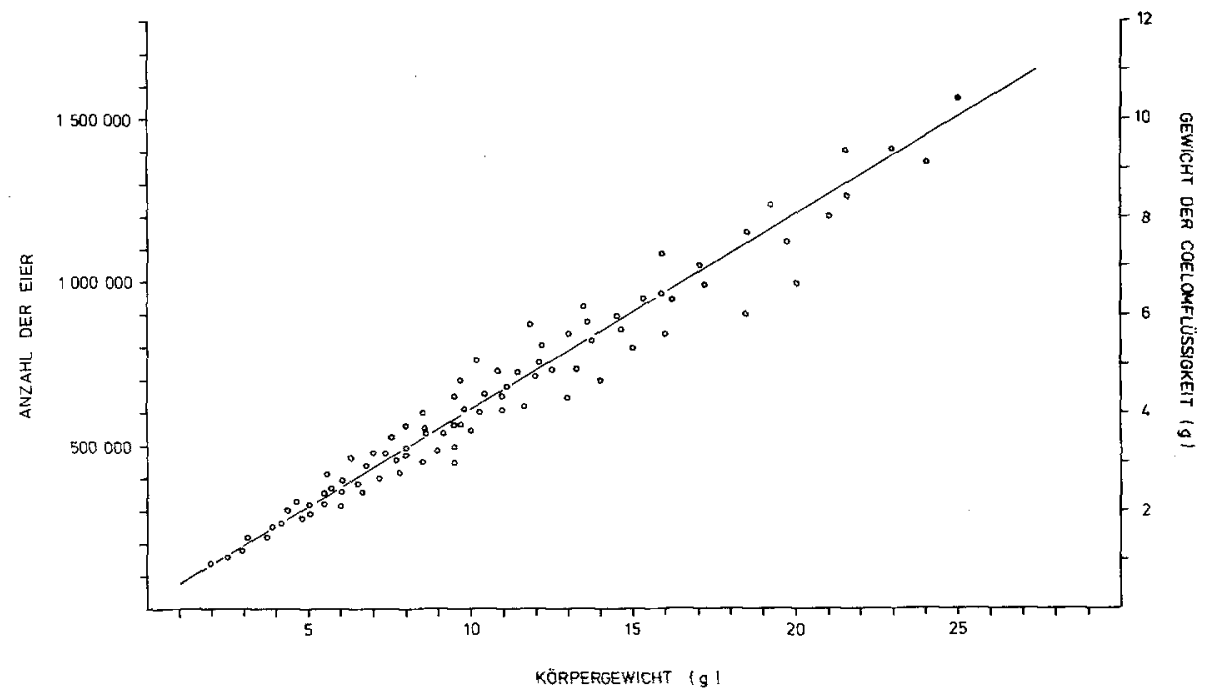

Abb. 17: Anzahl der ausgewachsenen Eier in Relation zum Körpergewicht (g Feuchtsubstanz) und Gewicht der Coelomflüssigkeit

sigkeit $15620 \pm 8 \%$ Eier. Die Relation zwischen Leibeshöhlenflüssigkeit, Anzahl der Eier und Körpergewicht der Tiere ist in der Abbildung 17 wiedergegeben. Danach enthielt der größte gefundene Wurm (33 g, Le Dossen I) 2 Millionen, der kleinste geschlechtsreife Wurm $(0,9 \mathrm{~g}$, Le Pouldu IX) hingegen nur 75000 Eier.

$\mathrm{Da}$ die Würmer der verschiedenen Biotope sich in ihrer mittleren Körpergröße erheblich unterscheiden, müssen auch Unterschiede in ihrer potentiellen Natalität beste- 
Energiehaushalt des Wattwurms

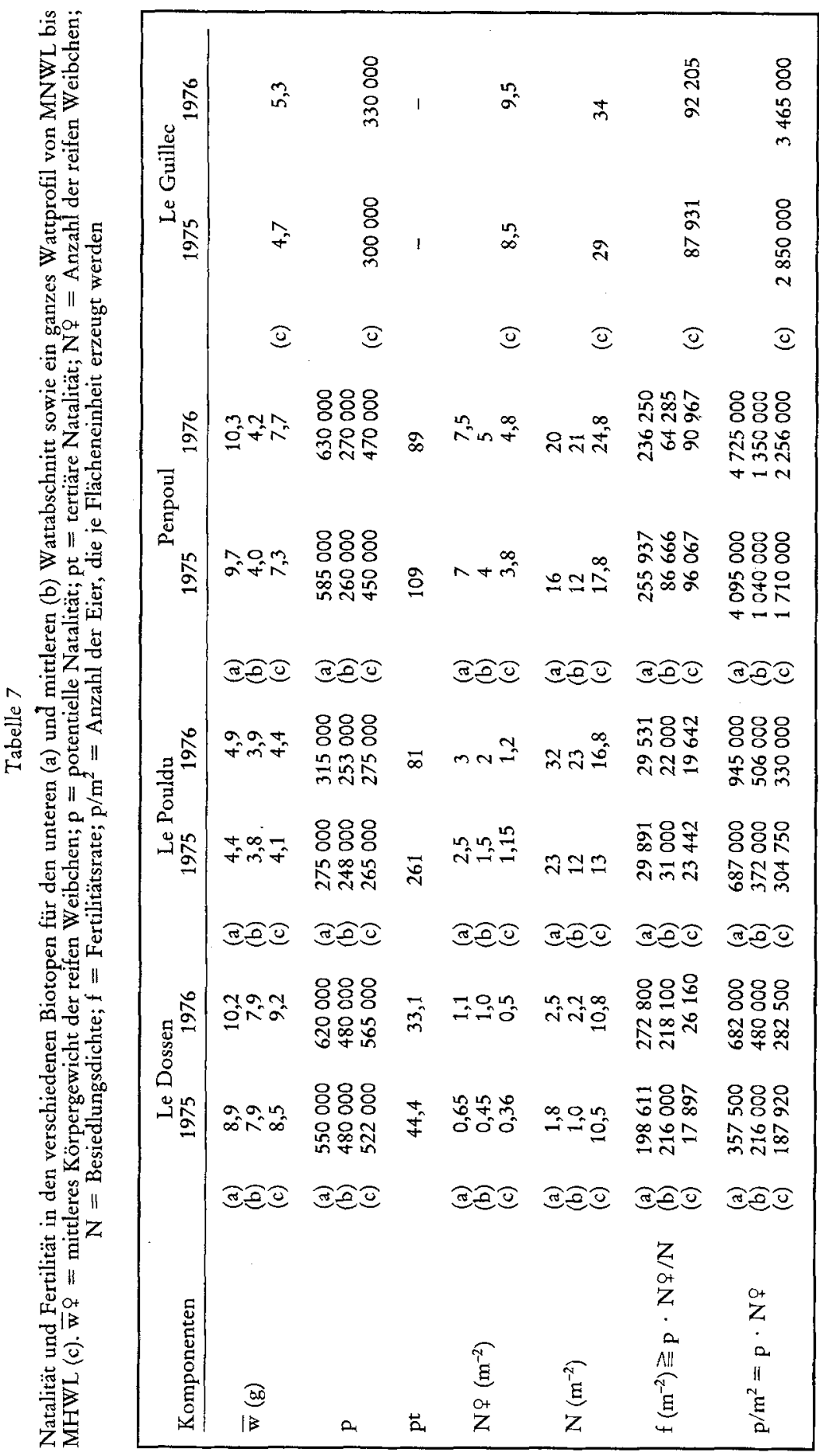


hen. Legt man der Berechnung alle reifen Weibchen des Wattprofils zugrunde, dann wurde die größte Natalität im Watt von Le Dossen ermittelt, gefolgt von Penpoul, Le Guillec und Le Pouldu (Tab. 7). Weiterhin stieg die potentielle Natalität generell mit abnehmendem Niveau des untersuchten Biotops. So wurden bei Le Dossen in Höhe der mittleren Niedrigwasserlinie $15 \%(29 \%)$ mehr Eier je Weibchen ermittelt als auf mittlerem Niveau (in Klammern die Werte des 2. Untersuchungsjahres). Ähnliche Werte ergaben sich für Le Pouldu (11 bzw. $24 \%$ ). Bei Penpoul wurde mit $125 \%$ der höchste Unterschied gemessen. 1976 war die potentielle Natalität in der Regel um 4 bis $12 \%$ höher als 1975.

Die Fertilitätsraten, die alle Mitglieder der Population berücksichtigen, sind naturgemäß kleiner als die oben genannten Werte (Tabelle 7). Die größte Differenz gegenüber der Natalität zeigte sich bei Le Pouldu, nicht nur für das ganze Wattprofil (91,2 bzw. 92,9\%), sondern auch für den mittleren (87,5 bzw. 91,3\%) und unteren $(89,7$ bzw. 90,6\%) Gezeitenabschnitt. Hier machte sich der große Anteil kleiner, indifferenter Tiere, welche auf allen Niveaus gefunden wurden, bemerkbar. Der Unterschied war im Hinblick auf das ganze Profil bei Le Dossen sogar noch etwas größer (96,6 bzw. 95,4\%), im mittleren (55 bzw. $55 \%$ ) und unteren ( 64 bzw. $66 \%$ ) Bereich war er hingegen erheblich geringer. Das Watt wies hier im Gegensatz zu den anderen Biotopen auch im oberen Abschnitt nur ein geringes Gefälle auf. Hierdurch ergab sich ein relativ breiter Streifen, der ausschließlich von kleinen, indifferenten Tieren besiedelt wurde. Der hohen Zahl indifferenter Tiere stand eine relativ geringe Menge geschlechtsreifer Tiere gegenüber, so daß sich eine geringe Fertilitätsrate ergab. Die Werte von Penpoul zeigten den höchsten Anteil geschlechtsreifer Weibchen an der Gesamtpopulation an. Die Fertilitätsrate betrug hier gegenüber der gleich $100 \%$ gesetzten Natalitätsrate für das ganze Profil 21,3 $(19,4) \% \mathrm{bzw}$. für den unteren 43 $(37,5) \%$ und den mittleren Gezeitenabschnitt 33,3 $(23,8) \%$.

Wenn man die Länge des Profils in die Rechnung einbezieht, kann man errechnen, wie viele Eier von der gesamten Population produziert wurden. Es waren dies, bezogen auf einen $1 \mathrm{~m}$ breiten von MNWL bis MHWL reichenden Streifen, bei Le Dossen 88153272 (132 520 750), Le Pouldu 80362575 (87021 000) und Penpoul 872100000 (1 150.560000$)$ Eicr. Diese werden dann nach Newell (1948) mit der Flut an den oberen Hang getrieben, wo sie ihre weitere Entwicklung durchmachen.

Diesen ungeheuer großen Eizahlen stehen nur relativ wenige überlebende Nachkommen gegenüber. So wurden im Sommer nach der Eiabgabe bei Le Dossen höchstens 44,4 (33,1), Le Pouldu 262 (81) und Penpoul 109 (89) Tiere der Jahresklasse 0 je Quadratmeter gezählt. Das bedeutet, daß nur etwa 0,0003 bis $0,00001 \%$ der reifen Eianlagen, falls sie befruchtet wurden, die embryonale und larvale Entwicklungsphase überlebten. Es ist mit einer hohen Befruchtungsrate zu rechnen, die gesichert wird durch die synchronisierte Abgabe der Geschlechtszellen und eine ungeheuer große Anzahl Spermien, die manchmal bei Niedrigwasser das Wasser in Ebbetümpeln weißlich färbt (Duncan, 1960; Newell, 1948; eigene Beobachtungen). Die sehr hohe Motalität während der Entwicklung ist wohl bedingt durch die im Winter und Frühjahr herrschenden rathen Umwelteinflüsse. Die Larven, welche im Oberflächensand leben, werden wahrscheinlich durch starke Wasserbewegungen und damit verbundenen Sedimentumlagerungen wiederholt aus dem Sand gespült. Sie werden dann in besonderem Maße durch die Rollbewegung der Sandkörner sowie durch Freßfeinde bedroht und sind in dieser Zeit sicher von größerer Bedeutung als Futtermittel für räuberische Arten. 


\section{DISKUSSION}

\section{Dispersion, Abundanz und Abundanzdynamik}

Die oben dargestellten quantitativen Studien zeigen, daß die Population der verschiedenen Untersuchungsgebiete sowohl gleiche als auch unterschiedliche Abundanz- und Verteilungsmerkmale aufweisen. So erstreckt sich die Zone mit der größten Besiedlungsdichte immer über den oberen Wattbereich, nämlich von der mittleren Nipphochwasserbis etwa $50 \mathrm{~cm}$ oberhalb der Mittelwasserlinie. Die Population setzt sich hier fast ausschließlich aus kleinen unreifen Individuen zusammen. Mit sinkendem Niveau nimmt auch die Besiedlungsdichte $a b$, wobei gleichzeitig das mittlere Gewicht der Tiere ansteigt. An zwei Biotopen steigen die Abundanzwerte im unteren Abschnitt wieder leicht an. Der Jahresmittelwert der Besiedlungsdichte für das mittel-lotische Watt von Le Pouldu ist etwa gleich groß wie der für den schwach-lotischen Port de Penpoul. Für das stark-lotische Watt von Le Dossen ist er hingegen um $44 \%$ kleiner. Weiterhin weichen die Werte der mittleren Jahresabundanz in den beiden aufeinanderfolgenden Jahren an allen Probenorten des unteren Gezeitenbereiches nur geringfügig voneinander ab. Im oberen Abschnitt der Biotope ist die Besiedlungsdichte im zweiten Jahr durchweg geringer als im ersten. Die Abweichung ist bei Le Pouldu mit 20 (Station VIII) und $26 \%$ (Station IX) am größten, gefolgt von Le Dossen mit 14 und $12 \%$. Im Port de Penpoul ist sie hingegen mit 2 und $6 \%$ verhältnismäßig gering.

Die Analyse der Gewichtsgruppendiagramme ergab, daß die Besiedlungsdichte der mittleren und großen Tiere wesentlich konstanter ist als die der kleinen. Da die juvenilen Individuen der Klasse 0 den oberen Gezeitenbereich für ihre Ansiedlung bevorzugen, finden auch hier die größten Abundanzschwankungen innerhalb eines Jahres und zwischen aufeinanderfolgenden Jahren statt. Als entscheidender beeinflussender Außenfaktor kommt hierfür wohl nur die Wasserbewegung, die unmittelbar über die Umlagerung des Sediments auf die Tiere einwirkt, in Frage. Alle anderen untersuchten Faktoren lassen sich nicht derart gut mit den beobachteten Abundanzschwankungen korrelieren. Besonders betroffen sind verständlicherweise die ganz kleinen postlarvalen Stadien, die nur wenige Zentimeter unter der Substratoberfläche leben. So lagert die auch bei ruhigem Wetter etwa $50 \mathrm{~cm}$ hohe Brandung bei Le Dossen das Sediment etwa $2 \mathrm{~cm}$ tief um, und die Besiedlungsdichte bleibt auch im oberen Gezeitenbereich immer relativ gering. Im geschützten Port de Penpoul, wo auch nach mittleren Stürmen keine Rippelbildung festzustellen ist, ist sie hingegen in beiden aufeinanderfolgenden Jahren relativ hoch. Besonders eindrucksvoll zeigt sich der Einfluß der Wasserbewegung im Watt von Le Pouldu. Hier ist im Frühling und Sommer 1975 keine Rippelbildung zu beobachten und die Besiedlungsdichte steigt an der Station IX auf die Rekordhöhe von 330 Individuen $/ \mathrm{m}^{2}$. Sie nimmt erst während der ersten leichten Herbststürme im September ab. Im darauffolgenden Jahr sind wesentlich mehr und stärkere Stürme zu verzeichnen, die selbst während der ruhigen Monate Mai bis August zu Sedimentumlagerungen von 2 bis $4 \mathrm{~cm}$ führen. Die Individuendichte nimmt nun wesentlich langsamer zu und bleibt zur Zeit der maximalen Besiedlung etwa $63 \%$ unter dem Wert des Vorjahres.

Eine Erklärung für den oben beschriebenen unterschiedlichen Verlauf der Abundanzkurven für den oberen bzw. mittleren und unteren Bereich der Untersuchungsgebiete ergibt sich, wenn man die Fortpflanzungsverhältnisse und Größenzusammensetzung der 
Populationen in die Betrachtung einbezieht. Die Besiedlungsdichte des oberen Gezeitenbereiches nimmt während der Wintermonate, besonders aber im Februar und März, stärker $\mathrm{ab}$ als in den vorangegangenen Monaten, wohingegen die des unteren und mittleren Bereiches zunimmt. Ein Vergleich mit der Gewichtsverteilung der Populationen zeigt, daß von der $\mathrm{Zu}$ - bzw. Abnahme besonders die kleinen 0,3 bis $1,5 \mathrm{~g}$ schweren Würmer betroffen sind. Es ist unwahrscheinlich, daß die Verringerung des Bestandes im oberen Bereich durch eine erhöhte Sterblichkeit bedingt ist, weil zu gleicher Zeit die Besiedlungsdichte der tiefer liegenden Wattbereiche zunimmt. Offensichtlich findet hier eine Verteilung der jungen Würmer vom oberen Watt über das ganze Watt hin statt. Diese Vermutung wird erhärtet durch eine im Frühjahr 1977 gemachte Beobachtung. Anfang April hatte sich an allen Biotopen die normalerweise in Höhe der extremen Nipphochwasserlinie liegende obere Besiedlungsgrenze auf ein bis zu $50 \mathrm{~cm}$ höher liegendes Niveau verschoben. Später ging diese Begrenzungslinie dann wieder zurück.

Im Port de Penpoul kann eine Wanderung der Würmer nicht direkt aus den Diagrammen der Abundanzdynamik abgeleitet werden. Jedoch ist auch hier im Februar bis Mai eine Verringerung der Anzahl der 0,3 bis 1,5 g schweren Würmer im oberen Watt, bei gleichzeitiger Zunahme der gleichen Gewichtsgruppe im mittleren und unteren Gezeitenbereich zu verzeichnen. Die Abundanzkurve für den oberen Bereich zeigt jedoch keinen Abfall, sondern sogar einen Anstieg, was durch die Tatsache zu erklären ist, daß sich hier, im Gegensatz zu den anderen Biotopen, bereits im Februar und März die winzigen Würmer aus der Herbstlaichperiode durch Haufenbildung bemerkbar machen und registriert werden.

Im Frühling und Sommer nimmt die Besiedlungsdichte des oberen Watts in allen Biotopen mehr oder weniger stark zu. Die Gewichtsgruppendiagramme zeigen, daß dies auf das massenhafte Auftreten der winzigen Würmer der 0-Gruppe zurückzuführen ist. Diese Tiere erscheinen aber im Port de Penpoul bereits ab Januar, in den anderen Biotopen hingegen erst im Mai. Hier scheint eine Korrelation zwischen dem Nahrungsangebot und der Entwicklungszeit bzw. dem Wachstum der Tiere vorzuliegen, die an späterer Stelle noch diskutiert wird.

Die oben beschriebene Verteilung der jungen Würmer vom oberen Hang über den ganzen Gezeitenbereich läßt sich nicht nur als passives Verfrachten durch Brandungseinwirkung und Sedimentumlagerung erklären, weil sie im gleichen Maße in den stark-, mittel- und schwach-lotischen Biotopen stattfindet. Weiterhin verbreiteten sich die Tiere im Frühjahr 1976 (Januar bis April) mit nur 4 Sturmtagen (Windgeschwindigkeit $\geqq 16 \mathrm{~m}$ / sec) ebenso wie im gleichen Zeitabschnitt des darauffolgenden Jahres mit 19 Sturmtagen. Es muß hier ein aktives Wanderverhalten angenommen werden.

Auch in der Literatur gibt es Hinweise dafür, daß Arenicola marina nicht so ortsfest ist, wie es allgemein angenommen wird. So fingen Meek \& Storrow (1924) im März freischwimmende Individuen im Planktonnetz, Fauvel (1899) beobachtete Tiere, die nachts ihre Röhren verließen, im freien Wasser umherschwammen und bei Beleuchtung schnell wieder das Substrat aufsuchten, und Thorson (1946) fand einige Exemplare auf der Wattoberfläche. Werner $(1954,1956)$ beschreibt die Winterwanderung kleiner und mittelgroßer Würmer, die im November bis Januar stattfindet und durch eine rasche Verringerung der Wassertemperatur ausgelöst wird. Als kritische Temperaturgrenze gibt Werner 1 bis $3{ }^{\circ} \mathrm{C}$ an. 
Ein rasches Absinken der Wassertemperatur auf unter $3{ }^{\circ} \mathrm{C}$ kann in der Gegend um Roscoff als auslösender Faktor ausgeschlossen werden, da die Temperatur bis auf höchstens $7{ }^{\circ} \mathrm{C}$ abfällt. Die Lufttemperatur, die hier im Februar und März ihre Tiefstwerte erreicht, käme hingegen sehr wohl in Betracht. Zur Zeit der Ebbe sind dann die Tiere zeitweise Temperaturen, die um den Gefrierpunkt liegen, ausgesetzt. Der auslösende Faktor könnte durch den starken Unterschied zwischen Luft- und Wassertemperatur, den der Wurm bei kommender Flut erleidet, gegeben sein. Zur Klärung dieser Probleme sind zu einem späteren Zeitpunkt entsprechende Experimente geplant.

\section{Wachstum, Ernährung und Produktion}

Das individuelle Wachstum variiert zum Teil sehr stark; sowohl von einem Biotop zum anderen als auch mit unterschiedlichem Höhenniveau eines Biotops. Im unteren und mittleren Wattabschnitt weisen die Tiere von Le Dossen die größten Zuwachsraten auf, gefolgt von denen von Penpoul und Le Pouldu. Im oberen Hang nehmen hingegen die Würmer von Penpoul und Le Pouldu stärker zu als die von Le Dossen. Generell nimmt die Wachstumsgeschwindigkeit mit ansteigendem Höhenniveau ab. Am größten ist der Unterschied bei Le Dossen, wo die Tiere des oberen Hanges einen 92- bis 94\%igen geringeren individuellen Gewichtszuwachs aufweisen als die des unteren Hanges.

Die Wachstumsraten sind während der Sommermonate Mai bis Oktober wesentlich größer als in der übrigen Zeit des Jahres. Weiterhin sind sie im zweiten Untersuchungsjahr um 6 bis $36 \%$ geringer als im ersten.

Vergleicht man diese Fakten mit dem herrschenden Faktorengefüge, so fällt zunächst einmal der starke Einfluß des Höhenniveaus und damit der Wasserbedeckungszeit auf. Obwohl Arenicola marina sich auch bei Niedrigwasser durch Häufchenbildung bemerkbar macht, scheint seine Haupternährungsphase doch in der Zeit der Wasserbedeckung zu liegen. Tauchbeobachtungen sowie Laborexperimente lassen jedoch keinen signifikanten Unterschied in der Freßaktivität, gemessen an der Menge des abgegebenen Kotstandes, zwischen Wasserbedeckungs- und Trockenliegephase erkennen. Dies deutet darauf, daß der Wurm nicht allein die im Sand enthaltenen Nährstoffe ausnutzt, sondern zusätzlich solche aus dem Oberflächenwasser gewinnt. Je länger nun die Wasserbedeckungsperiode dauert, desto mehr Nahrung können die Tiere aus dem Wasser aufnehmen und desto größer ist der Zuwachs. Im oberen Bereich des stark-lotischen Watts von Le Dossen wurde eine nur etwa halb so große mittlere individuelle Wachstumsrate wie in den anderen Biotopen auf gleichem Niveau ermittelt. Hier müssen die Tiere sicherlich einen nicht unerheblichen Teil ihrer durch Nahrung gewonnenen Energie aufwenden, um die durch dauernde Sedimentumlagerungen ganz oder teilweise zerstörten Wohnröhren wiederaufzubauen.

Unterschiedliche Wachstumsraten innerhalb eines Jahres und zwischen aufeinanderfolgenden Jahren lassen sich jedoch nicht mit Hilfe der Wasserbedeckungszeit erklären, sondern in erster Linie durch das Nahrungsangebot. So weisen sowohl das Sediment als auch das Oberflächenwasser im Sommer einen höheren Gehalt an organisch gebundenem Kohlenstoff auf als im Winter. Ebenso ist dieser 1975/76 im Jahresmittel höher als 1976/77.

Die Nahrung sedimentfressender Tiere kann sich aus verschiedenen Komponenten 
zusammensetzen: junge Individuen der Makrofauna, Angehörige des Mesopsammons, einzellige Algen, Pilze, Bakterien sowie partikuläre und gelöste organische Substanzen. Uber die relative Bedeutung der einzelnen Bestandteile ist nichts bekannt.

Longbottom (1970) wies nach, daß A. marina keine Cellulase bildet und Kristensen (1972) zeigte, daß die Verdauungsenzyme nur in geringem Maße wenige Karbohydrate hydrolysieren (so Amylose, Glycogen, Laminaran und Dextran). Hieraus ist zu schließen, daß Pflanzenmaterial, außer Bakterien und Diatomeen, keine Bedeutung für die Ernährung des Wurmes hat. Eine Aufspaltung von Cellulose mit Hilfe von Bakterien ist unwahrscheinlich, da der Sand nach Kermack (1955) nur etwa 15 Minuten lang im Körper bleiben soll. Auch fand Longbottom (1970) im Lumen des Darmes keine Amöbocyten. Inwieweit eine intrazelluläre Verdauung in der Darmwand wirksam ist, läßt sich schwer beurteilen, da die Hauptmasse des Sandes wegen der schnellen Beförderung nur kurz mit der Darmwand in Berührung kommt.

Die einfachste Methode, um die Art der Nahrung aufzuschlüsseln, stellen Untersuchungen des Darminhaltes dar. Dazu wurden im Sommer 1977 etwa 50 Würmer sofort an der Ausgrabungsstelle (Port de Penpoul) durch einen Längsschnitt geöffnet und der Sand sowohl dem Oesophagus als auch dem Rectum entnommen und in Seewasser suspendiert. Zur besseren Identifizierung wurden die Mikroorganismen mit Bengalrosa 0,1 bis $1 \%$ in $5 \%$ Phenol) und Neutralrot angefärbt. Bengalrosa ist ein spezifisches Färbemittel für Bakterien (Zobell, 1946) und Neutralrot erlaubt, lebende Diatomeen von toten zu unterscheiden. Während sich der Farbstoff bei lebenden Zellen in Vakuolen sammelt, färbt sich bei toten Zellen der ganze Zelleib an.

Der Oesophagus enthielt regelmäßig neben Detritus und Pflanzenresten einige wenige Diatomeen, viele Bakterien, wenige Ciliaten und selten kleine Nematoden. Der Sand des Enddarms enthielt keine Ciliaten, hingegen Detritus, Pflanzenreste, lebende Bakterien und Diatomeen und wenige Nematoden. Die Anzahl der Bakterien und Diatomeen war jedoch deutlich kleiner als im Sand des Oesophagus.

Diese Beobachtungen weisen auf eine hohe Bedeutung der Ciliaten als Nahrung hin. Weiter können auch Bakterien und Diatomeen als solche nicht ausgeschlossen werden.

Einige Erfahrungen, die bei der Aufzucht der Würmer in Kultivierungskästen gemacht wurden, weisen in die gleiche Richtung. Es ist möglich, die Tiere im Aquarium in mit Sand gefüllten Behältern zu halten, jedoch ist hier in der Regel kein Gewichtszuwachs zu verzeichnen. So überlebten 3 von ursprünglich 35 Tieren die zweijährige Untersuchungszeit, davon hatte eines nur leicht zugenommen, die anderen hingegen abgenommen. Andere Forscher berichten ähnliches (Duncan, 1960). Wiederholte Untersuchungen der Oberflächenschicht zeigten nun, daß der Sand zwar ungefähr die gleiche Menge an Detritus, Bakterien, organisch gebundenem Kohlen- und Stickstoff wie im Freiland enthielt, daß jedoch die Anzahl der Vertreter des Mesopsammons, besonders die der Ciliaten stark reduziert war. Ähnliche Beobachtungen zeigten sich anfänglich bei den Aufzuchtversuchen im Freiland. Erst, nachdem der Versuchsaufbau abgeändert wurde und die Kästen nach dem Einsetzen mit einer unzerstörten Schicht Oberflächensand versehen wurden, zeigten die Würmer ähnliche Zuwachsraten wie sie aus den Gewichtsgruppendiagrammen abgeleitet werden konnten.

Die ökologischen Studien lassen weiterhin eine enge Korrelation zwischen der Besiedlungsdichte des Mesopsammons, besonders der Ciliata einerseits und Wachstum und 
Produktion der Würmer andererseits erkennen. So sind die größten Zuwachs- und Produktionsraten im Sommer zu verzeichnen, wenn auch die Mesopsammon-Individuendichte am größten ist. Weiterhin sind sowohl die Ciliatenbesiedlungsdichte als auch Wachstum und Produktion im zweiten Untersuchungsjahr geringer als im ersten. Schließlich werden die größten Produktionswerte an Probenorten ermittelt, die eine reiche Ciliatenfauna aufweisen, wie z. B. Penpoul I und IX, Le Dossen I, Le Pouldu IX und Le Guillec III. Probenorte mit geringerer Ciliatenbesiedlung weisen auch geringe Produktionswerte auf. Hier ist besonders Penpoul V zu nennen, wo die Besiedlungsdichte der Ciliaten trotz des sehr hohen Gehaltes an Detritus, Pflanzenresten, Bakterien sowie organisch gebundenem Kohlen- und Stickstoff stets gering bleibt. Die Würmer sind hier durchschnittlich nur halb so schwer wie bei Le Dossen auf gleichem Niveau und weisen relativ geringe Zuwachsraten auf.

Im unteren Bereich des Watts von Le Pouldu, wo hohe Abundanz- und Produktionswerte, jedoch niedrige Zuwachsraten $\mathrm{zu}$ verzeichnen sind, wird wahrscheinlich ebenfalls das Angebot an Ciliaten als wachstumsbegrenzender Faktor wirksam, zumal hier eine große Anzahl anderer Polychaeta siedelt, die als Nahrungskonkurrenten in Frage kämen. Zur Überprüfung dieser Hypothese wurden im April 197720 Tiere der Jahresklasse 2 von Le Pouldu III nach Penpoul III übersiedelt und hier in Kultivierungskästen gehalten. Ein Vergleich der Zuwachsraten zeigt deutlich, daß die Tiere im Port de Penpoul mehr zunahmen als bei Le Pouldu (Tab. 8).

Tabelle 8

Vergleich der Zuwachsraten der nach Penpoul III verpflanzten Tiere mit denen der dort und bei Le Pouldu lebenden Tieren

\begin{tabular}{lccc|}
\hline & \multicolumn{2}{c|}{ Mittleres Gewicht der Jahresklasse 2 } & Gewichtszunahme \\
Probenort & April 1977 & Oktober 1977 & $(\mathrm{g})$ \\
\hline Le Pouldu III & 2,4 & 5,4 & 2,9 \\
Penpoul III & 6,5 & 14,3 & 7,8 \\
verpflanzte Tiere & 2,5 & 7,1 & 4,6 \\
\hline
\end{tabular}

Natürlich wird neben dem Niveau und Nahrungsangebot auch die Temperatur einen Einfluß auf das Wachstum und die Produktion ausüben, denn bei poikilothermen Organismen folgen bekanntlich Stoffwechselvorgänge der RGT-Regel. Dieser Einfluß ist wahrscheinlich jedoch gering, denn die Wirkung der Temperatur auf den Sauerstoffverbrauch von A. marina ist gekennzeichnet durch eine Reihe von Unstetigkeiten, deren Effekt es ist, die Atmung unter verschiedensten Bedingungen nahezu konstant zu halten (Krüger, 1964). Da Aktivität, Stoffwechsel und Wachstum des Wurmes ohne Zweifel in engem Zusammenhang zur Atmungsgröße stehen, bedeutet dies zugleich, daß sie während des ganzen Jahres unter den in seinem Biotop herrschenden Temperaturbedingungen nur in geringem Maße schwanken. Die geringe Schwankungsbreite der Aktivität zeigt sich ja auch tatsächlich in der Freß- und Kotabgabeaktivität, welche nur geringe saisonabhängige Variationen erkennen lassen.

Als weiterer wichtiger Außenfaktor, der oft in seiner beeinflussenden Wirkung unterschätzt wird, ist hier noch der Niederschlag zu nennen. Anscheinend schützt sich der 
Wurm gegen den schädigenden Einfluß des Süßwassers, indem er seine Wohnröhre verschließt und seine Aktivität vermindert, denn bei Regen ist die Kotabgabeleistung stark herabgesetzt. Die damit verbundene verringerte Freßaktivität und Nahrungsaufnahme scheint sich direkt auf Wachstum und Produktion auszuwirken, denn die geringeren Zuwachsraten im źweiten Untersuchungsjahr gegenüber dem ersten korrelieren mit einer fast doppelt so großen Niederschlagsmenge und der doppelten Anzahl von Regentagen im Jahr.

Den übrigen noch nicht genannten Faktoren wie Korngrößenzusammensetzung des Sediments, Porenvolumen, Gehalt an Wasser und Luft, Salz- und Sauerstoffgehalt sowie $\mathrm{pH}-$ Wert des Wassers kommt in den untersuchten Biotopen mit Ausnahme von Le Guillec I wohl keine direkte Bedeutung zu, weil die für A. marina schädlichen Werte nicht erreicht werden. Eine indirekte Wirkung ist ihnen natürlich nicht abzusprechen, denn feinkörnige Sedimente enthalten größere Mengen an organischer Substanz als grobkörnige und interstitielle Organismen benötigen ein gewisses Ausmaß an Porenvolumen usw.

Der Probenort Le Guillec I, der unmittelbar neben dem Flußbett liegt, ist täglich starken Salzgehaltsschwankungen unterworfen, die von 28,3\% $\mathrm{S}$ im interstitiellen Wasser bis $\mathrm{zu} 32,6 \% \mathrm{~S}$ im Oberflächenwasser reichen. Hinzu kommt, daß das Sediment, im Vergleich zu anderen Probenorten den sehr geringen Grad an Wassersättigung von $79 \%$ unter normalen und $54 \%$ unter extremen Bedingungen sowie eine geringe Besiedlung durch Ciliaten aufweist. Die Abundanzwerte bleiben unter diesen Bedingungen stets gering, und die Würmer erreichen nur eine mittlere Größe. Juventile Tiere werden hier niemals gefunden.

A. marina ist zwar generell als euryhalin anzusehen, denn er kommt noch in brackigen Gewässern mit einem Salzgehalt von 10\% (wie in der Ostsee) vor, jedoch verhindern Tagesvariationen von über $4 \% \mathrm{~S}$ eine als normal anzusehende Besiedlung. Zu ähnlichen Ergebnissen kam Amoureux (1966), der an verschiedenen Küstengebieten eine maximale Variationsbreite von 4 bis $6 \% \mathrm{~S}$ ermittelte.

A. marina ist der bedeutendste Sekundärproduzent aller untersuchter Biotope. Bei Le Dossen werden im unteren, mittleren und oberen Bereich 60, 45 und $64 \%$ der gesamten Makrofauna-Produktion durch diese Art bestritten. Für das Watt von Le Pouldu liegen die entsprechenden Werte bei -, 73 und $94 \%$, für den Port de Penpoul bei 92,31 und $81 \%$ und für Le Guillec III bei $54 \%$.

Tabelle 9 zeigt einen Vergleich der Produktionswerte der Arenicola-Populationen aus der Umgebung von Roscoff mit anderen Invertebraten-Populationen des Gezeitenbereiches. A. marina ist danach der größte Produzent aller bisher untersuchten Polychaeta und Gastropoda und übertrifft in seiner Produktionsleistung auch viele Bivalvia.

Interessant ist schließlich noch ein Vergleich von Biomasse und Körpergröße der Tiere verschiedener Küsten. Beukema (1976) ermittelte im holländischen Wattenmeer eine Biomasse von 3,5 bis $6,1 \mathrm{~g} \mathrm{~m}^{-2}$ (Trockensubstanz), Holme (1949) im Exe Estuary (England) $47,8 \mathrm{~g} \mathrm{~m}^{-2}$ (Feuchtsubstanz) und Thamdrup (1935) bei Skalling (Dänemark) Höchstwerte von 86 bis $172 \mathrm{~g} \mathrm{~m}^{-2}$ (Feuchtsubstanz). Diese Werte werden von allen untersuchten Populationen bei Roscoff, mit Ausnahme der des Watts von Le Dossen, zum Teil erheblich übertroffen.

Auch zur Körpergröße liegen sehr unterschiedliche Angaben vor. Thamdrup (1935) ermittelte bei Skalling (Dänemark) ein mittleres Gewicht von 4 bis 4,5 g, Smidt (1951) im 


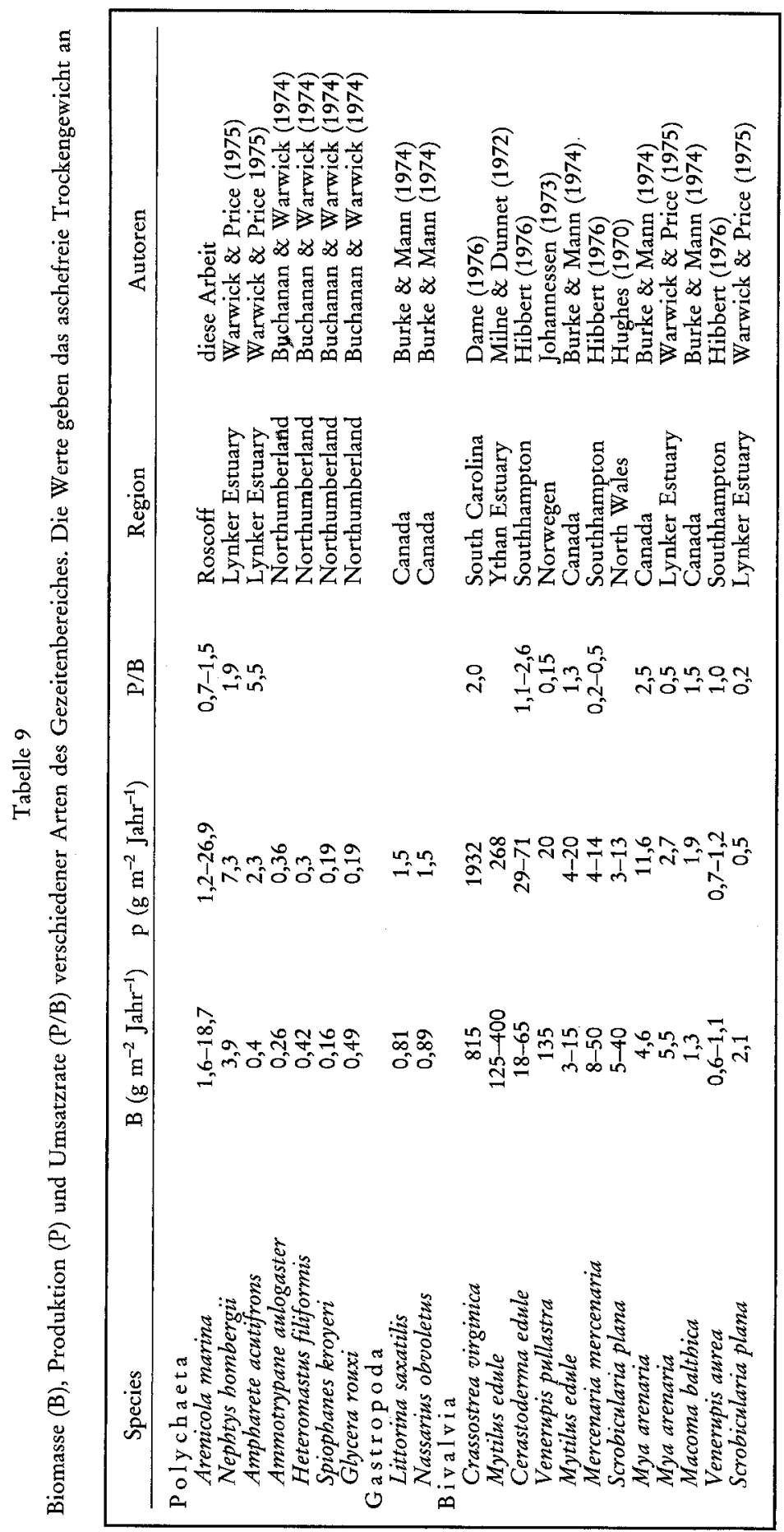


dänischen Wattenmeer eine durchschnittliche Körperlänge der nicht kontrahierten Tiere von 17 bis $18 \mathrm{~cm}(13 \mathrm{~g}$ ), mit einer Variationsbreite von 8 bis $28 \mathrm{~cm}$ ( 3 bis $20 \mathrm{~g}$ ). (in Klammern die kalkulierten Körpergewichte), Duncan (1959) an verschiedenen englischen Küstengebieten ein mittleres Körpervolumen von 1,1 bis $8,3 \mathrm{~cm}^{3}(1,2$ bis $9,2 \mathrm{~g})$ und Brenning (1965) bei Langenwerder (Ostsee) ein solches von 1,9 bis $4,1 \mathrm{~cm}^{3}$ (2,1 bis $4,4 \mathrm{~g}$ ). Weiterhin waren die größten Würmer, die bei Helgoland und Sylt gefunden wurden, 18,8 und 26,5 g schwer (Krüger, 1964).

Verglichen mit diesen Daten stehen die Würmer von Roscoff durchaus nicht am Anfang der Größenskala, sondern nehmen fast einen Mittelplatz ein. Die in den untersuchten Biotopen ermittelte größere Biomasse ist daher wohl im wesentlichen auf höhere Besiedlungszahlen zurückzuführen. Allerdings wurden bei Roscoff vereinzelt größere Individuen gefunden als in der Nordsee. So hatten die schwersten Würmer von Le Dossen und Penpoul ein Gewicht von 30,4 bzw. 29,1 g. Leider können die für die obengenannten Daten zugrunde liegenden ökologischen Zusammenhänge nicht diskutiert werden, weil in den vorliegenden Arbeiten das Gefüge der Außenfaktoren nur selten umfassend dargestellt wurde. Es fehlen insbesondere Angaben zur Wasserbewegung und Sedimentumlagerung sowie eine Bestandsaufnahme der begleitenden Sandlïckenfauna.

\section{Energiefluß}

Die Tatsache, daß Arenicola marina ein Sandfresser ist, hat zu der naheliegenden Auffassung geführt, daß der Wurm die im Sand enthaltenen Nahrungsstoffe ausnutzt. Die Vermutung, daß die Reduktionszone, in die der Wohnbau des Wurmes hineinreicht, erhebliche Mengen organischer Substanz enthalte, bestärkte diese Auffassung. Im typischen Falle besteht der ausgeworfene Kot aus Oberflächensand, in den nur gelegentlich kleine Abschnitte reduzierten Sandes eingelagert sind. Da der Wurm normalerweise Oberflächensand frißt, spielt der Gehalt des darunterliegenden Sediments an organischem Material höchstens eine untergeordnete Rolle. In den im Rahmen dieser Arbeit untersuchten Biotopen lag der Gehalt des Tiefensandes an organischer Substanz in der gleichen Größenordnung wie der des Oberflächensandes. Vergleicht man nun den Gehalt des Kotsandes an organisch gebundenem Stickstoff und Kohlenstoff mit dem des Oberflächenund Tiefensandes, so weist der Kotsand stets die höchsten Werte auf. Allerdings ist das Verhältnis von $\mathrm{C} \mathrm{zu} \mathrm{N}$ im Kotsand gegenüber dem Oberflächen- und Tiefensand derart verschoben, daß im Kotsand besonders der Kohlenstoff und in geringerem Maße der Stickstoffgehalt erhöht ist. Hieraus ist zu schließen, daß der Wurm vor allem stickstoffreiche Substanzen, also tierisches Material, verwertet.

Die Anreicherung des Kotsandes mit organischer Substanz läßt sich mit Hilfe der Filtrationshypothese erklären. Wells (1945) beschrieb erstmals, daß der Wurm mit Hilfe der über seinen Körper gleitenden Kontraktionswellen einen kontinuierlichen Wasserstrom durch seinen Wohnbau pumpt. Dieser tritt durch die unter dem Kothaufen liegende Offnung in den Wohngang ein und verläßt ihn auf dem Weg durch den Sandstrang wieder. Krüger $(1957,1971)$ wies nach, daß der Wasserstrom durch die Filterwirkung des Sandes von den darin suspendierten Substanzen befreit wird. Wahrscheinlich dichtet der Wurm 

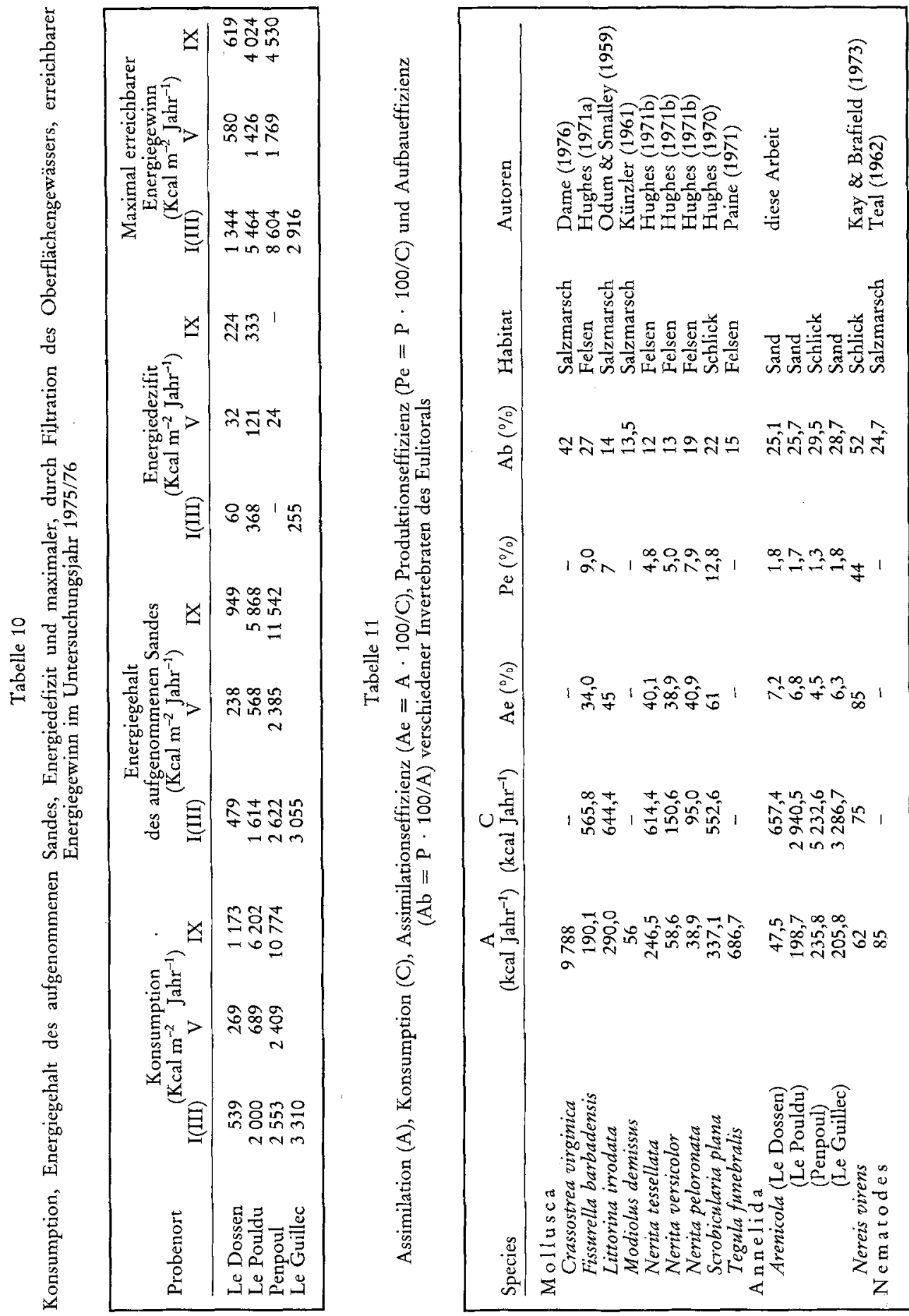
durch Abgabe von Schleim die Lücken im Sand weitgehend ab, so daß auch feine kolloidale Partikel zurückgehalten werden. Es wird also in der Freßregion organisches Material angereichert, welches der Wurm zusammen mit dem Sand frißt.

Es erhebt sich nun die Frage, welchen Anteil des Nahrungsbedarfs die Filtration im Sandstrang deckt. Da der konsumierte Energiebetrag und die aufgenommene Sedimentmenge sowie deren Energiegehalt bekannt sind, kann der noch fehlende Energiebedarf, der wahrscheinlich durch Filtration aus dem Oberflächenwasser gedeckt wird, leicht errechnet werden (Tab. 10). Da weiterhin die Pumpleistung des Wurmes bekannt ist und der Gehalt des Oberflächenwassers an organisch gebundenem Kohlenstoff sowie dessen Energieäquivalent ermittelt wurden (Pollack, 1978), läßt sich der durch Filtration erreichbare Energiegewinn errechnen. Wenn man der Kalkulation die durchschnittliche Pumpleistung eines $5 \mathrm{~g}$ schweren Wurmes von $30 \mathrm{ml} / \mathrm{h}$ (bei $15^{\circ} \mathrm{C}$ ) zugrunde legt (Krüger, 1971), liegt er bei $13,1 \mathrm{cal}$ je Gramm Wurmgewicht und Stunde. Die entsprechenden Werte für die untersuchten Biotope und Stationen sind unter Berücksichtigung der Wasserbedeckungszeit ebenfalls in Tabelle 10 aufgeführt. Es zeigt sich, daß der durch Filtration gewonnene Energiebetrag das Energiedefizit in der Regel um das Zehnfache übertrifft und damit bei weitem ausreicht, dieses zu decken. Lediglich am Probenort IX von Le Dossen wird das Energiedefizit nur um das Dreifache übertroffen, und hier sind auch die geringsten Zuwachsraten zu verzeichnen.

Bei diesen Berechnungen sind verschiedene Momente nicht berücksichtigt: (1) Die Pumpleistung kleiner Würmer ist nicht bekannt. Es wurde hier ein lineares Verhältnis von Körpergröße und Pumpleistung angenommen. Bekannt ist, daß A. marina seine Pumpaktivität um ein Mehrfaches steigern kann und daß der Gehalt des Wassers an organischen Partikeln einen Einfluß auf die Pumpaktivität hat (Krüger, 1964). (2) Die ermittelten Werte des Gehaltes an organischen Substanzen im Oberflächenwasser sind Minimumangaben. Wahrscheinlich sind sie an der Bodenoberfläche größer, denn es werden durch die Wellenbewegung Mikro- und Meioorganismen aufgewirbelt und mit dem Wasserstrom in den Wohnbau gezogen. Weiterhin reichert der Wasserstrom den Freßteil der Röhre mit Sauerstoff an, wodurch Organismen aus der sauerstoffarmen Umgebung angelockt werden können. Schließlich verdaut der Wurm wahrscheinlich, aufgrund seiner Enzymausstattung und der kurzen Verweildauer im Darm, nur einen Bruchteil der abgefilterten organischen Substanzen.

Tabelle 11 zeigt einen Vergleich verschiedener Daten zum Energiehaushalt von $A$. marina und anderer bereits untersuchter Arten des Gezeitenbereiches. Auffallend sind hier die relativ hohen Werte der Konsumption und die geringen der Assimilations- und Produktionseffizienz, die ihrerseits durch die hohe Konsumption bedingt sind. Bei $A$. marina ist die aufgenommene Energiemenge bei gleicher Assimilation um fast eine Zehnerpotenz größer als die der anderen Arten. Die Werte der Aufbaueffizienz weichen hingegen nicht wesentlich von denen der anderen Arten ab. Die hohen Konsumptionswerte können mit Hilfe der Ernährungsweise des Wurms erklärt werden. A. marina ist ein nicht-selektionierender Sedimentfresser, und ein Großteil der sich im Sediment befindlichen organischen Substanz ist für ihn aus den obengenannten Gründen nicht verwertbar. Es sind daher einfach große Konsumptionsraten erforderlich, damit der Nahrungsbedarf gedeckt wird. Leider können diese Daten nicht mit denen anderer sedimentfressender Arten verglichen werden, weil entsprechende Untersuchungen bisher nicht vorliegen. 


\section{Entwicklung der Geschlechtszellen und Ablaich- termin}

Die Größenentwicklung der Geschlechtszellen kann in drei Abschnitte unterteilt werden. Nach der Abgabe ins Coelom wachsen die Gameten während der Frühlingsmonate langsam, bis sie etwa 40 bis $50 \mu \mathrm{m}$ (Eizelle) bzw. 40 bis $45 \mu \mathrm{m}$ (Spermienplatte) groß sind. Es folgt eine Phase schnelleren Wachstums, die, sobald die Geschlechtsprodukte einen Durchmesser von 150 bis $160 \mu \mathrm{m}$ (Eizelle) bzw. 80 bis $90 \mu \mathrm{m}$ (Spermienplatte) erreicht haben, wieder in langsameres Wachstum übergeht. Die Phase schnellen Wachstums der Oocyten und Spermatogonien beginnt im stark-lotischen Watt von Le Dossen zeitlich am spätesten und verläuft dann am schnellsten, so daß hier der steilste Anstieg der Wachstumskurven resultiert. Im schwach-lotischen Port de Penpoul beginnt sie zeitlich früher und dauert etwas länger. Im mittel-lotischen Watt von Le Pouldu beginnt die Hauptwachstumsphase der Oocyten am frühesten und verläuft dann am langsamsten, die der Spermatogonien beginnt hingegen ein bis zwei Monate später und dauert dann ebenso lange wie die der Oocyten. Die an den anderen Gebieten beobachtete Phase langsameren Wachstums kann bei Le Pouldu nur bei den Oocyten festgestellt werden.

In allen Biotopen beginnt die Phase des schnellen Wachstums an den am tiefsten gelegenen Untersuchungsstationen am ehesten und verläuft am schnellsten. Die Wachstumsgeschwindigkeit verlangsamt sich mit ansteigendem Niveau.

Die Abgabe der Geschlechtszellen erfolgt in den verschiedenen Biotopen zu unterschiedlichen Zeiten und dauert unterschiedlich lange. Sie begann 1975 bei Penpoul Anfang Oktober und erstreckte sich über zwei Monate. Bei Le Pouldu begann sie Anfang Oktober, bei Le Guillec Anfang November und bei Le Dossen Anfang Dezember und dauerte jeweils einen Monat lang. 1976 setzte die Ablaichperiode an allen Biotopen früher ein, dauerte aber länger und schloß etwa zum gleichen Zeitpunkt ab wie im Vorjahr.

Die Entwicklung der Geschlechtszellen wird bei vielen Polychaeta durch Hormone gesteuert, welche im supra-oesophagalen Ganglion gebildet werden (Zusammenfassung bei Clark, 1965; Clark \& Olive, 1973). Bei A. marina konnten bisher keine Hormone festgestellt werden, welche Proliferation und Wachstum der Gametocyten beeinflussen. Erst kurz vor dem Ablaichen wird ein die Reifung stimulierendes Hormon wirksam, dessen Anwesenheit bei den Oocyten den Eintritt in die Metaphase I der Meiose und bei den Spermienplatten die Trennung der Spermatozoa von der Morula bewirkt. Wenn diese Vorgänge vollzogen sind, werden die Geschlechtszellen von den Nephromixae ins Außenmedium abgegeben. Das Hormon kann erst kurz vor dem Ablaichtermin aus dem Prostomium extrahiert werden. Nach dem Ablaichen wird die Hormonproduktion eingestellt (Howie, 1966; Howie \& McClenaghan, 1965).

Nach den Angaben verschiedener Autoren (Duncan, 1960; Howie, 1959; Newell, 1948; Pirlot, 1933; Storrow, 1925) ist die Laichperiode auf wenige Tage im Herbst beschränkt. Nach anderen Angaben kann sie sich auch über mehrere Wochen (Cazaux, 1966) oder sogar Monate (Brenning, 1965) erstrecken. Während in einigen Fällen das Ablaichen im Juli oder August beginnt (Cazalix, 1966), nennen andere Autoren die Monate Oktober bis Dezember (Ashworth, 1904; Kyle, 1896; Orton, 1933; Smidt, 1951; Thamdrup, 1935). Drei Angaben liegen vor, die eine Laichperiode im Frühjahr (Januar bis Mai) vermerken (Gamble \& Ashworth, 1898; Howie, 1959; Kyle, 1896). Für das plötzliche 
Ablaichen werden oft Mondphasen, die über die Gezeiten auf die Tiere einwirken, oder ein starker Temperatursturz verantwortlich gemacht. Der unterschiedliche Beginn der Reifung, Verlauf der Wachstumskurven, Beginn der Ablaichperiode und deren Dauer an den verschiedenen Biotopen machen eine Beurteilung der Einwirkung von Außenfaktoren auf die Hormonproduktion sehr schwierig. Eine Einwirkung der Temperatur oder Mondphase wäre denkbar, würde aber bedeuten, daß die Tiere von Penpoul auf den ersten starken Temperaturabfall oder Springtide reagieren, die Würmer der anderen Biotope jedoch nicht. Das dürfte aber unwahrscheinlich sein. Eine Klärung der hier angeschnittenen Probleme ist wohl nur experimentell herbeizuführen. Möglicherweise wird die Abgabe der Geschlechtszellen gar nicht durch einen abiotischen Stimulus ausgelöst, sondern ähnlich wie bei Platynereis dumerili und Glycera convoluta (Boilly-Marer, 1969) durch Pheromone, die von überreifen Individuen abgegeben werden.

Danksagungen. An dieser Stelle möchte ich allen, die diese Arbeit unterstützt haben, herzlich danken. In besonderem Maße gilt dieser Dank meinem verehrten Lehrer, Herrn Professor Dr. Hans Mergner, für seine Beratung, freundliche Förderung und große Hilfsbereitschaft und Monsieur le Professeur Bergerard, dem Direktor der Biologischen Station Roscoff, der mir einen zweijährigen Aufenthalt in der Station ermöglichte und mir Zugang zu sämtlichen Einrichtungen und Arbeitsgeräten der Station verschaffte. Nicht zuletzt danke ich meiner Frau, die mir bei allen Arbeiten stets tatkräftig zur Seite stand. Ohne ihre Hilfe wären Untersuchungen in einem solchen Umfang nicht möglich gewesen.

\section{ZITIERTE LITERATUR}

Amoureux, L., 1966. Étude bionomique et écologique de quelques Annelides Polychaetes des sables intertidaux des côtes ouest de la France. Archs Zool. exp. gén. 107, 1-218.

Ashworth, J. H., 1904. Arenicola (the lugworm). L. M. B. C. Mem. typ. Br. mar. Pl. Anim. 11, 1-118.

Beukema, J. J., 1976. Biomass and species richness of the macrobenthic animals living on the tidal flats of the Dutch Waddensea. Neth. J. Sea. Res. 10, 236-261.

Boilly-Marer, Y. I., 1969. Recherches expérimentales sur la danse nuptiale de Platynereis dumerilii. Origine et modalités d'action de la substance excitatrice. Cah. Biol. mar. 10, 255-269.

Brenning, U., 1965. Beiträge zum Gonadenzyklus von Arenicola marina (L.) (Annelida, Polychaeta) im Raum der Wismar-Bucht. Wiss. Z. Univ. Rostock 14, 633-643.

Buchanan, J. B. \& Warwick, R. M., 1974. An estimate of benthic macrofaunal production in the offshore mud of the Northumberland coast. J. mar. biol. Ass. U. K. 54, 197-222.

Burke, M. V. \& Mann, K. H., 1974. Productivity and production: biomass ratios of bivalve and gastropod populations in an eastern Canadian estuary. J. Fish. Res. Bd Can. 31, 167-177.

Callame, B., 1955. Sur la repartition de Arenicola marina L. dans les sediments de la zone intercotidale. C. r. hebd. Séanc. Acad. Sci., Paris 240, 1670-1672.

Cazaux, C., 1966. Evolution d'une population d'Arenicola marina (L.) a Arcachon. Cycle annuel Periode de reproduction. Act. Soc. linn. Bordeaux 103, 3-18.

Chapman, G. \& Newrell, G. E., 1949. The distribution of Lugworms (Arenicola marina) over the flats of Whitstable. J. mar. biol. Ass. U. K. 28, 627-635.

Clark, R. B., 1965. Endocrinology and the reproductive biology of Polychaetes. Oceanogr. mar. Biol. 3, 211-255.

- \& Olive, P. J. W., 1973. Recent advances in polychaete endocrinology and reproductive biology. Oceanogr. mar. Biol. 11, 175-222.

Crips, D. J., 1971. Energy flow measurements. In: Methods for the study of marine benthos. Ed. by N. A. Holme \& A. D. Blackwell. Oxford, 334 pp. (IBP Handbook Nr. 16).

Dame, R. F., 1976. Energy flow in an intertidal oyster population. Estuar. coast. mar. Sci. 4, 243-253. 
Duncan, A., 1960. Spawning of Arenicola marina (L.) in the British Isles. Proc. zool. Soc. Lond. 134, 137-156.

- 1959. Local races in lugworms (Arenicola marina). Nature, Lond. 184, 71-72.

Gamble, F. W. \& Ashworth, I. H., 1898. The habits and structure of Arenicola marina. Q. Jl microsc. Sci. 41, 1-43.

Hibbert, C. J., 1976. Biomass and production of a bivalve community on an intertidal mud-flat. J. exp. Biol. Ecol. 25, 249-261.

Holme, N. A., 1949. The fauna of sandy mud banks near the mouth of the Exe estuary. J. mar. biol. Ass. U. K. 28, 189-237.

Howie, D. I. D., 1959. The spawning of Arenicola marina. I. The breeding season. J. mar. biol. Ass. U. K. 38, 395-406.

- 1966. Further data relating to the maturation hormone and its site of secretion in Arenicola marina. Gen. comp. Endocrinol. 6, 347-361.

- \& McClenaghan, C. M., 1965. Evidence for a feedback mechanism influencing spermatogonial division in the lugworm (Arenicola marina [L.]). Gen. comp. Endocrinol. 5, 40-44.

Hughes, R. N., 1970. An energy budget for a tidal flat population of the bivalve Scrobicularia plana (Da Costa). J. Anim. Ecol. 39, 357-379.

- 1971a. Ecological energetics of Nerita populations on Barbados, West Indies. Mar. Biol. 11, 12-22.

- 1971b. Ecological energetics of the keyhole limpet Tissurella barbadensis. J. exp. mar. Biol. Ecol. 6, $167-178$.

Ivlev, V. S., 1934. Eine Mikromethode zur Bestimmung des Kaloriengehaltes von Nährstoffen. Biochem. Z. 275, 49-55.

Johannessen, O. H., 1973. Length and weight relationships and the potential production of the bivalve Venerupis pullastra (Montagu) on a sheltered beach in western Norway. Sarsia 53, 41-48.

Kay, D. G. \& Brafield, A. E., 1973. The energy relations of the Polychaete Neanthes (= Nereis) virens (Sars). J. Anim. Ecol. 42, 673-692.

Kermack, D. M., 1955. The anatomy and physiology of the gut of the polychaete Arenicola marina. Proc. zool. Soc. Lond. 125, 347-381.

Kisseleva, M. J., 1972. Dynamique et production de la population des polychaetes. Platynereis dumerilii dans la biocoenose des Cystoséires en Mer Noire. Trav. Mus. Hist. nat. Gr. Antipa 11, 49-58.

Klein, G., Rachor, E. \& Gerlach, S. A., 1975. Dynamics and productivity of two populations of the benthic tube-dwelling amphipod Ampelisca brevicornis (Costa) in Helgoland Bight. Ophelia 14, 139-159.

Kristensen, J. H., 1972. Carbohydrases of some marine invertebrates with notes on their food and on the natural occurrence of the carbohydrates studied. Mar. Biol. 14, 130-142.

Krüger, F., 1957. Der Wohnbau von Arenicola als Filtereinrichtung. Naturwissenschafren 44, 597.

- 1959. Zur Ernährungsphysiologie von Arenicola marina. Zool. Anz. (Suppl. Bd) 22, 115-120.

- 1964. Versuche über die Abhängigkeit der Atmung von Arenicola marina (Annelida, Polychaeta) von Größe und Temperatur. Helgoländer wiss. Meeresunters. 10, 38-63.

- 1971. Bau und Leben des Wattwurms Arenicola marina. Helgoländer wiss. Meeresunters. 22, 149-200.

Kuenzler, E. J., 1961. Structure and energy flow of a mussel population in a Georgia salt marsh. Limnol. Oceanogr. 6, 191-204.

Kyle, H. M., 1896. On the nephridia, reproductive organs and postlarval stages of Arenicola marina. Ann. Mag. nat. Hist. (Ser. 6) 18, 295-300.

Lang, K., 1955. Anorganische Stoffe. In: Handbuch der physiologisch- und pathologisch-chemischen Analyse. Hrsg. von E.-F. Hoppe-Seyler \& H. Thierfelder. Springer, Berlin, 3 (1), 1-190.

Linke, O., 1939. Die Biota des Jadebusenwattes. Helgoländer wiss. Meeresunters. 1, 201-348.

Longbottom, M. R., 1970a. The distribution of Arenicola marina (L.) with particular reference to the effects of particle size and organic matter of the sediments. J. exp. mar. Biol. Ecol. 5, 138-157.

- 1970b. Distribution of digestive enzymes in the gut of Arenicola marina. J. mar. biol. Ass. U. K. 50, 121-128.

Massé, H., 1971. Etude quantitative des sables fins intfalittoraux de l'etang de Berre. Evaluation de la production de quelques espèces. Vie Milieu (Suppl.) 22, 329-364. 
Meek, A. \& Storrow, B., 1924. On a pelagic phase of Arenicola marina and of Eteone arctica. Ann. Mag. nat. Hist. 14, 453-455.

Milne, H. \& Dunnet, G. M., 1972. Standing crop, productivity and trophic relations of the fauna of the Ythan Estuary. In: The estuarine environment. Ed. by Barnes R. S. K. \& J. Green, Appl. Science Publs, London, 86-106.

Newell, G. E., 1948. A contribution to our knowledge of the life history of Arenicola marina. J. mar. biol. Ass. U. K. 27, 554-580.

Nichols, F. H., 1975. Dynamics and energetics of three deposit feeding bentic invertebrate populations in Puget Sound, Washington. Ecol. Monogr. 45, 57-82.

Odum, E. P. \& Smalley, A. E., 1959. Comparison of population energy flow of a herbivorous and deposit-feeding invertebrate in a salt marsh ecosystem. Proc. natn. Acad. Sci. U.S.A. 45, 617-622.

Orton, J. H., 1933. Observation on Arenicola marina. Nature, Lond. 132, 409-411.

Paine, R. T., 1971. Energy flow in a natural population of the herbivorous gastropod Tegula funebralis. Limnol. Oceanogr. 16, 86-98.

Peer, D. L., 1970. Relation between biomass, productivity and loss to predators in a population of a marine benthic polychaete Pectinaria byperborea. J. Fish. Res. Bd Can. 27, 2143-2153.

Pirlot, J. M., 1933. La ponte de l'Arenicola marina L. à la côte Belge. Bull. Mus. r. Hist. nat. Belg. 9, $49,1-7$.

Pirrie, M. E., Bruce, J. R. \& Moore, H. B., 1932. A quantitative study of the fauna of the sandy beach at Port Erin. J. mar. biol. Ass. U. K. 18, 279-296.

Pollack, H. A., 1978. Populationsdynamik, Produktivität und Energiehaushalt des Wattwurms Arenicola marina in der Umgebung von Roscoff. Diss., Bochum, 367 pp.

Rachor, E., 1976. Structure, dynamics and productivity of a population of Nucula nitidosa (Bivalvia, Protobranchiata) in the German Bight. Ber. dt. wiss. Kommn Meeresforsch. 24, 296-331.

Rullier, F., 1959. Etude bionomique de l'Aber de Roscoff. Trav. Stan biol. Roscoff 10, 1-346.

Smalley, A. E., 1960. Energy flow of a salt marsh grashopper population. Ecology 41, 672-677.

Smidt, E. L. B., 1951. Animal production in the Danish Waddensea. Meddr Kommn Danm. Fisk.-og Havunders. (Fiskeri) 11, 1-151.

Storrow, B., 1925. Faunistic notes. Rep. Dove mar. Lab. 14, 57.

Teal, J. M., 1962. Energy flow in the salt marsh ecosystem of Georgia. Ecology 43, 614-624.

Thamdrup, H. M., 1935. Beiträge zur Ókologie der Wattenfauna auf experimenteller Grundlage. Meddr Kommn Danm. Fisk.-og Havunders. (Fiskeri) 10, 1-125.

Thorson, G., 1946. Reproduction and larval development of danish marine invertebrates, with special reference to the planctonic larvae in the Sound (Øresund). Meddr Kommn Danm. Fisk.-og Havunders. (Plankton) 4, 1-523.

Vooys, C. G. N., 1975. Glycogen and total lipids in the lugworm (Arenicola marina) in relation to reproduction. Neth. J. Sea Res. 9, 311-319.

Walkley, A. \& Black, I. A., 1934. An examination of the Degtjareff method for determination soil organic matter, and a proposed modification of the chromic acid titration method. Soil Sci. 37, 29-38.

Warwick, R. M. \& Price, R., 1975. Macrofauna production in an estuarine mud flat. J. mar. biol. Ass. U. K. 55, 1-18.

Wells, G. P., 1945. The mode of life of Arenicola marina. J. mar. biol. Ass. U. K. 26, 170-207.

Werner, B., 1954. Eine Beobachtung über die Wanderung von Arenicola marina L. (Polychaeta sedentaria). Helgoländer wiss. Meeresunters. 5, 93-102.

- 1956. Uber die Winterwanderung von Arenicola marina L. (Polychaeta sedentaria). Helgoländer wiss. Meeresunters. 5, 353-378.

Wohlenberg, E., 1937. Die Wattenmeer-Lebensgemeinschaften im Königshafen von Sylt. Helgoländer wiss. Meeresunters. 1, 1-92.

Zobell, C. E., 1946. Marine microbiology. Chronica Botanica Comp., Waltham, Mass., 240 pp. 